This is the accepted author manuscript of the publication

\title{
Ether analogues of DPA-714 with subnanomolar affinity for the translocator protein (TSPO).
}

By Banister SD, Wilkinson SM, Longworth M, Stuart J, Apetz N, English K, Brooker L, Goebel C, Hibbs DE, Glass M, Connor M, McGregor IS, Kassiou M.

Published in Eur J Med Chem. 2015 Mar 26;93:392-400.

doi: 10.1016/j.ejmech.2015.02.004

Direct link to the final version of the article:

http://www.sciencedirect.com/science/article/pii/S0223523415000896

A CC-BY-NC-ND license apply to this work. 


\title{
Ether analogues of DPA-714 with subnanomolar affinity for the translocator protein (TSPO)
}

\author{
Samuel D. Banister, ${ }^{\mathrm{a}, \mathrm{b}}$ Corinne Beinat, ${ }^{\mathrm{a}, \mathrm{b}}$ Shane M. Wilkinson, ${ }^{\mathrm{b}}$ Bin Shen, ${ }^{\mathrm{a}}$ Cecilia Bartoli, ${ }^{\mathrm{c}}$ \\ Silvia Selleri, ${ }^{\mathrm{c}}$ Eleonora Da Pozzo, ${ }^{\mathrm{d}}$ Claudia Martini, ${ }^{\mathrm{d}}$ Frederick T. Chin, ${ }^{\mathrm{a}}$ and \\ Michael Kassiou ${ }^{* b, e}$
}

\begin{abstract}
${ }^{\mathrm{a}}$ Department of Radiology, Stanford University School of Medicine, Stanford, CA 94305, USA; ${ }^{\mathrm{b}}$ School of Chemistry, The University of Sydney, Sydney, NSW 2006, Australia; 'Department of Pharmaceutical Sciences, University of Florence, Via U. Schiff, 650019 Polo Scientifico Sesto Fiorentino, Italy; ${ }^{\mathrm{d} D e p a r t m e n t ~ o f ~}$ Pharmacy, University of Pisa, Via Bonanno 6, 56127 Pisa, Italy, ${ }^{\mathrm{e}}$ Faculty of Health Sciences, The University of Sydney, Sydney, NSW 2006, Australia.
\end{abstract}

\begin{abstract}
Sixteen new phenyl alkyl ether derivatives $(\mathbf{1 2}, \mathbf{1 4 - 2 8})$ of the 5,7-dimethylpyrazolo[1,5a]pyrimidin-3-ylacetamide (DPA) class were synthesized and evaluated in a competition binding assay against $\left[{ }^{3} \mathrm{H}\right] \mathrm{PK} 11195$ using $18 \mathrm{kDa}$ translocator protein (TSPO) derived from rat kidney mitochondrial fractions. All analogues showed superior binding affinities for TSPO compared to DPA-713 (5) and DPA-714 (6). Picomolar affinities were observed for this class of TSPO ligands in this assay for the first time, with phenethyl ether $\mathbf{2 8}$ showing the greatest affinity $\left(K_{\mathrm{i}}=0.13 \mathrm{nM}\right)$. Additionally, all analogues increased pregnenolone biosynthesis (134-331\% above baseline) in a rat C6 glioma cell steroidogenesis assay.
\end{abstract}

Keywords: translocator protein, pyrazolo[1,5-a]pyrimidine, DPA-714, steroid, positron emission tomography

\section{Introduction}

The $18 \mathrm{kDa}$ translocator protein (TSPO) is a five transmembrane domain protein subunit of a multimeric complex located primarily in the outer mitochondrial membrane, and is mainly responsible for the translocation of cholesterol from the outer- to inner-mitochondrial membrane.[1, 2] TSPO is widely expressed in peripheral organs, especially in steroidogenic tissues. Normal TSPO expression in the brain is minimal,[3] but several neuropathologies (including stroke, Alzheimer's disease, and Parkinson's disease) are associated with an overexpression of TSPO in the brain.[4] TSPO is currently thought to be a biomarker for microglial activation and neuroinflammation,[5] as well as a potential therapeutic target for neurological and psychiatric disorders.[4, 6-8]

Beyond its role in cholesterol metabolism and steroid biosynthesis, TSPO is also involved in cell proliferation and apoptosis.[8] The overexpression of of TSPO has been observed in numerous human cancers, particularly breast cancer.[9-11] For breast cancers, TSPO expression changes with cancer progression, and is associated with aggressive phenotypes.[12] In the case of neuroblastoma, TSPO ligands were able to induce apoptosis and cell cycle arrest, and offer sensitization to chemotherapy.[13] For these reasons, TSPO has been promoted as a novel target for cancer imaging as well as cancer therapies.[14, 15] 
One of the earliest and most widely explored TSPO ligands is the quinoline carboxamide PK11195 (1, Fig. 1). The affinity of PK11195 for TSPO is in the nanomolar range in both rat $\left(K_{\mathrm{i}}=3.0 \mathrm{nM}\right)[16]$ and human $\left(K_{\mathrm{i}}=4.5-22.3 \mathrm{nM}\right)$.[17, 18] Another structural class of high affinity TSPO ligands are the substituted acetanilides typified by DAA1106 (2).[19] DAA1106 demonstrates picomolar affinity for rat TSPO $\left(K_{\mathrm{i}}=0.0726 \mathrm{nM}\right)$, [17] but obvious species differences exist for this compound, and reduced affinities are observed for human TSPO $\left(K_{\mathrm{i}}=0.2-13.1 \mathrm{nM}\right)$. [17, 20] The structurally-related acetamide PBR28 (3) shows a TSPO species difference comparable to 2 , with greater affinity for rat TSPO $\left(K_{\mathrm{i}}=0.7 \mathrm{nM}\right)$ than human TSPO $\left(K_{\mathrm{i}}=2.5-4.0 \mathrm{nM}\right) .[17,18,20]$ More recently, tetrahydrocarbazole GE-180 $\left(4, K_{\mathrm{i}}=0.87 \mathrm{nM}\right)$ was identified as part of a program to reduce the lipophilicity of a tetracyclic lead structure,[21] and $\left[{ }^{18} \mathrm{~F}\right] \mathrm{GE}-180$ is currently under investigation as a TSPO PET imaging agent.

The 5,7-dimethylpyrazolo[1,5-a]pyrimidin-3-ylacetamide (DPA) scaffold has been used to generate selective, drug-like ligands targeting TSPO. The most well-characterized examples of this class are DPA-713 $\left(5, K_{\mathrm{i}}=4.7 \mathrm{nM}\right.$ vs. $\left[{ }^{3} \mathrm{H}\right] \mathbf{1}$ in TSPO derived from rat kidney) and DPA-714 $\left(\mathbf{6}, K_{\mathrm{i}}=7.0 \mathrm{nM}\right.$ vs. $\left[{ }^{3} \mathrm{H}\right] \mathbf{1}$ in TSPO derived from rat kidney).[22-24] In a quinolinic acid model of excitotoxic injury in rat, 5 and $\mathbf{6}$ inhibited microglial activation and increased neuronal survival, indicating neuroprotective effects.[25] Additionally, $\left[{ }^{11} \mathrm{C}\right] \mathbf{5}$ and $\left[{ }^{18} \mathrm{~F}\right] \mathbf{6}$ have demonstrated utility as radiotracers for PET imaging of TSPO in humans, highlighting the in vivo suitability of the DPA class for diagnostic and therapeutic drug development.[26-31]

Previous structure-activity relationship (SAR) studies of the DPA class of TSPO ligands have focused on the generation of analogue libraries containing variation of the pyrazolopyrimidine core and amide group, with limited exploration of the phenyl alkyl ether region.[22, 32, 33] The present study systematically explored the steric and electronic tolerance of the TSPO binding site for the ether region of DPA-713 and DPA-714, with the aim of utilizing the obtained SAR information to guide the development of increasingly potent analogues of DPA-713 and DPA-714 for therapeutic investigation, as well as high affinity structures amenable to the incorporation of $\mathrm{C}-11$ and $\mathrm{F}-18$ radioisotopes as PET imaging candidates. To this end, analogues of DPA-713 and DPA-714 containing aliphatic, alicyclic, and aromatic groups as pendant substituents, at various distances from the ether linkage, were prepared.

\section{INSERT FIGURE 1}

\section{Synthetic chemistry}

The synthesis of novel DPA analogues (Scheme 1) is based on a scalable general method recently developed in our laboratories.[34] Commercial methyl 4-hydroxybenzoate (7) was quantitatively protected as its isopropyl ether (8), and treated with the conjugate base of acetonitrile to generate cyanoacetophenone 9. Deprotonation of 9 to the corresponding enolate, followed by treatment with excess $N, N$-diethylbromoacetamide, gave crude $\mathbf{1 0}$, which was immediately condensed with hydrazine to yield aminopyrazole 11. Condensation of 11 with acetylacetone generated the pyrazolopyrimidine core of 12, and subsequent cleavage of the isopropyl ether using aluminum chloride afforded common phenolic precursor 13. Alkylation of $\mathbf{1 3}$ was achieved by mild heating in the presence of the 
appropriate alkyl bromide and potassium carbonate, to cleanly furnish DPA analogues 14-28 in $37-90 \%$ yield following purification by flash chromatography or recrystallization.

\section{INSERT SCHEME 1}

\section{Results and discussion}

The synthesized DPA analogues 14-28 and PK11195 were evaluated for TSPO affinity using a membrane binding assay with $\left[{ }^{3} \mathrm{H}\right] \mathrm{PK} 11195$ as the competitive radioligand, and mitochondrial fractions from rat kidney as the TSPO source. The results are summarized in Table 1. The selectivity of DPA-713, DPA-714, and several simple $n$-alkyl analogues for TSPO was previously demonstrated by examining binding to the central benzodiazepine receptor (CBR) using $\left[{ }^{3} \mathrm{H}\right] \mathrm{Ro15,1788}$ and rat brain tissue.[24] Several simple alkyl ether analogues from the DPA structural class of TSPO ligands were shown to possess selectivity over CBR as well as numerous other common CNS targets.[24] Off-target activity of these novel DPA analogues was not determined since the aim of the present study was to explore SARs specifically for the ether region of the DPA class of TSPO ligands.

\section{INSERT TABLE 1}

The DPA analogues containing simple branched alkyl ethers, such as an isopropyl $\left(\mathbf{1 2}, K_{\mathrm{i}}=\right.$ $2.2 \mathrm{nM})$ or isobutyl $\left(\mathbf{1 4}, K_{\mathrm{i}}=2.4 \mathrm{nM}\right)$ group, showed similar affinities to DPA-713 and DPA$714\left(K_{\mathrm{i}}=4.7 \mathrm{nM}\right.$ and $7.0 \mathrm{nM}$, respectively), suggesting some steric tolerance at the TSPO binding site. TSPO binding was improved by the introduction of alicyclic rings, with a cyclobutyl $\left(15, K_{\mathrm{i}}=0.86 \mathrm{nM}\right)$ or cyclopentyl $\left(\mathbf{1 6}, K_{\mathrm{i}}=1.5 \mathrm{nM}\right)$ ether both conferring low- or subnanomolar affinities. The synthesis of cyclopropyl and cyclohexyl analogues from bromocyclopropane and bromocyclohexane was attempted, however, these alkylations proceeded slowly and only traces of expected ether compound could be obtained after several days of reaction at $40{ }^{\circ} \mathrm{C}$. Attempts to increase reaction rate by elevating temperature resulted in the formation of significant quantities of unidentified by-products.

Spacing the alicyclic group from the phenyl ether by a single methylene unit gave a homologous alicyclic series featuring a cyclopropyl (17), -butyl (18), -pentyl (19), or -hexyl ring (20). As with the alkyl congeners, TSPO binding affinities for this series were in the low nanomolar range $\left(K_{\mathrm{i}}=1.4-3.6 \mathrm{nM}\right)$, further confirming steric tolerance at the complementary TSPO binding site.

Given the nanomolar affinity of 20, it was hypothesized that benzylic ethers might also furnish high affinity TSPO ligands. Additionally, such compounds offer the potential for physicochemical "fine-tuning" by judicious incorporation of substituents around the ring, as well as the incorporation of pendant carbon-11 and fluorine-18 isotopes for PET imaging. The simplest benzylic DPA analogue, $21\left(K_{\mathrm{i}}=0.99 \mathrm{nM}\right)$, demonstrated comparable binding affinity to the alkyl and alicyclic derivatives. Systematic introduction of a fluorine atom to 21 to give all possible fluorobenzyl regioisomers resulted in picomolar TSPO binding in each case. A 2-fluoro substituent $\left(\mathbf{2 2}, K_{\mathrm{i}}=0.31 \mathrm{nM}\right)$ produced the greatest TSPO affinity, followed by the $3-\left(\mathbf{2 3}, K_{\mathrm{i}}=0.47 \mathrm{nM}\right)$ and 4-positions $\left(\mathbf{2 4}, K_{\mathrm{i}}=0.77 \mathrm{nM}\right)$. Similar regioisomeric incorporation of the more electronegative and sterically demanding trifluoromethyl group was less effective. Although only a 3-trifluoromethyl group (26, $\left.K_{\mathrm{i}}=0.67 \mathrm{nM}\right)$ conferred subnanomolar binding, analogues containing a trifluoromethyl group in the $2-\left(\mathbf{2 5}, K_{\mathrm{i}}=1.4\right.$ 
$\mathrm{nM})$ or 4-position $\left(27, K_{\mathrm{i}}=1.6 \mathrm{nM}\right)$ retained low nanomolar affinities. Further homologation of 21 produced the most high affinity pyrazolopyrimidine TSPO ligand thus identified, phenethyl DPA derivative $28\left(K_{\mathrm{i}}=0.13 \mathrm{nM}\right)$.

All new DPA-714 analogues were evaluated for their ability to increase pregnenolone biosynthesis in rat C6 glioma cells using a well-established steroidogenesis assay.[22, 35] Compounds 12, 14-28, and PK11195 were tested at the same concentration (40 $\mu \mathrm{M})$ to allow direct comparison of steroidogenic efficacy. After a two hour incubation period, pregnenolone was quantified using radioimmunoassay (RIA). The results are shown in Figure 2 , and a complete table of the data is available in the SI.

\section{INSERT FIGURE 2}

All new DPA analogues, as well as PK11195, increased pregnenolone production. Rates of pregnenolone biosynthesis increased from $134-331 \%$ of that induced by drug vehicle (DMSO) alone. Of the aliphatic and alicyclic DPA-714 analogues, cyclopentyl ether 16 and methylene-spaced cyclobutyl derivative 18 sho wed the highest efficacy (273\% and 298\% respectively). Isobutyl ether $\mathbf{1 4}$ and methylene-spaced cyclopropryl derivative $\mathbf{1 7}$ have similar lipophilicities and steric demands and demonstrated similar efficacy in this assay (206\% and 226\% respectively). All other aliphatic and alicyclic ether analogues showed were approximately as efficacious as PK11195 (166\%). Excluding 22 and 27, all benzylic and phenethyl DPA-714 analogues demonstrated greater than $230 \%$ increase in pregnenolone biosynthesis, with (2-trifluoromethyl)benzyl 25 proving the most potent (331\%).

A correlation between binding affinity and steroidogenic efficacy was established and is plotted in Figure 3. The relationship was significant when all new ligands (12 and 14-28) were included, however, correlation was improved by exclusion of 22 as an outlier (details of each analysis are available in Figures S2 and S3 of the SI). Despite having the second highest binding affinity of the series $\left(K_{\mathrm{i}}=0.31 \mathrm{nM}\right), 22$ was also the second least efficacious DPA714 analogue in the pregnenolone biosynthesis assay (162\%) after 20 (134\%).

\section{INSERT FIGURE 3}

These results suggest that binding affinity is linked to steroidogenic activity for ether analogues of DPA-714 possessing similar binding modes.

\section{Conclusion}

All novel DPA analogues showed higher affinity for TSPO than DPA-713 and DPA-714, with 28 showing the greatest improvement, and 20 showing the least. The improvements to TSPO binding for the series ranged from 1.3 to 36 times compared to DPA-713, and 1.9 to 53 times for DPA-714. The high affinities of benzylic congeners 22-27 indicate that substituents of varying electron density are tolerated at all positions around the ring. The low- or subnanomolar affinities of $\mathbf{1 2}$ and 14-28 collectively indicate broad steric and electronic tolerance by the TSPO binding site for the phenyl alkyl ether region of DPA-713 and DPA714. In particular, the high affinities of 21-28, and potent steroidogenic activities of 21, 2326, and 28, suggest that ring-substituted benzylic analogues of DPA-714 may offer new directions for the development of novel, high affinity TSPO ligands with potential therapeutic applications. 


\section{Experimental procedures}

\subsection{General chemistry details}

All reactions were performed under an atmosphere of nitrogen or argon unless otherwise specified. Dichloromethane was distilled from calcium hydride. Commercially available chemicals were used as purchased. Analytical thin layer chromatography (TLC) was performed using Merck aluminum-backed silica gel 60 F254 $(0.2 \mathrm{~mm})$ plates which were visualized using shortwave $(254 \mathrm{~nm})$ and/or longwave $(365 \mathrm{~nm})$ ultra-violet fluorescence. Flash chromatography was performed using Merck Kieselgel 60 (230-400 mesh) silica gel. Melting points were measured in open capillaries using a Stuart SMP10 Melting Point Apparatus and are uncorrected. Infrared absorption spectra were recorded on a Bruker ALPHA FT-IR spectrometer, and the data are reported as vibrational frequency $\left(\mathrm{cm}^{-1}\right)$. Nuclear magnetic resonance spectra were recorded at $300 \mathrm{~K}$ using either a Bruker AVANCE DRX400 (400.1 MHz) or AVANCE III 500 Ascend (500.1 MHz) spectrometer. The data is reported as chemical shift $(\delta \mathrm{ppm})$ relative to the residual protonated solvent resonance, relative integral, multiplicity $(\mathrm{s}=$ singlet, $\mathrm{br} \mathrm{s}=$ broad singlet, $\mathrm{d}=$ doublet, $\mathrm{t}=$ triplet, $\mathrm{q}=$ quartet, sep $=$ septet, $\mathrm{m}=$ multiplet $)$, coupling constants $(\mathrm{JHz})$, and assignment. Assignment of signals was assisted by COSY, DEPT, HSQC, and HMBC experiments where necessary. Low resolution mass spectra (LRMS) were recorded using electrospray ionization (ESI) recorded on a Finnigan LCQ ion trap spectrometer. Elemental analysis was obtained from the Chemical Analysis Facility in the Department of Chemistry and Biomolecular Sciences, Macquarie University, Australia.

\subsubsection{2-(2-(4-Isopropoxyphenyl)-5,7-dimethylpyrazolo[1,5-a]pyrimidin-3-yl)- $N, N$ - diethylacetamide (12)}

Compound 12 was synthesized from methyl 4-hydroxybenzoate (7) in 5 steps and 43\% overall yield using a previously described procedure.[34] m.p. $163-164{ }^{\circ} \mathrm{C} ; \mathrm{R}_{f} 0.53\left(\mathrm{CHCl}_{3}\right.$ $\mathrm{MeOH}, 90: 10) ;{ }^{1} \mathrm{H}$ NMR (500 MHz, $\left.\mathrm{CDCl}_{3}\right) \delta 7.74(2 \mathrm{H}, \mathrm{d}, J=9.0 \mathrm{~Hz}, \mathrm{ArH}), 6.96(2 \mathrm{H}, \mathrm{d}, J=$ $9.0 \mathrm{~Hz}, \mathrm{ArH}), 6.49(1 \mathrm{H}, \mathrm{s}, \mathrm{ArH}), 4.59(1 \mathrm{H}, \mathrm{sep}, J=6.1 \mathrm{~Hz}, \mathrm{OCH}), 3.90\left(2 \mathrm{H}, \mathrm{s}, \mathrm{ArCH}_{2}\right), 3.49$ $\left(2 \mathrm{H}, \mathrm{q}, J=7.0 \mathrm{~Hz}, \mathrm{NCH}_{2}\right), 3.40\left(2 \mathrm{H}, \mathrm{q}, J=7.0 \mathrm{~Hz}, \mathrm{NCH}_{2}\right), 2.73\left(3 \mathrm{H}, \mathrm{s}, \mathrm{ArCH}_{3}\right), 2.53(3 \mathrm{H}, \mathrm{s}$, $\left.\mathrm{ArCH}_{3}\right), 1.35\left(6 \mathrm{H}, \mathrm{d}, J=6.1 \mathrm{~Hz}, \mathrm{OCHCH}_{3}\right), 1.19\left(3 \mathrm{H}, \mathrm{t}, J=7.0 \mathrm{~Hz}, \mathrm{CH}_{2} \mathrm{C}_{3}\right), 1.12(3 \mathrm{H}, \mathrm{t}, J$ $\left.=7.0 \mathrm{~Hz}, \mathrm{CH}_{2} \mathrm{CH}_{3}\right) ;{ }^{13} \mathrm{C} \mathrm{NMR}\left(125 \mathrm{MHz} \mathrm{CDCl}_{3}\right) \delta 170.3(\mathrm{C}=\mathrm{O}), 158.3\left(\mathrm{C}_{\text {quat. }}\right), 157.6$ $\left(\mathrm{C}_{\text {quat. }}\right), 154.3$ ( $\left.\mathrm{C}_{\text {quat }}\right), 147.8$ ( $\left.\mathrm{C}_{\text {quat. }}\right), 144.8\left(\mathrm{C}_{\text {quat. }}\right), 130.1(2 \mathrm{C}, \mathrm{CH}), 126.2\left(\mathrm{C}_{\text {quat. }}\right), 116.1(2 \mathrm{C}$, $\mathrm{CH}), 108.2(\mathrm{CH}), 100.9$ (C quat. $), 70.0(\mathrm{OCH}), 42.4\left(\mathrm{NCH}_{2}\right), 40.7\left(\mathrm{NCH}_{2}\right), 28.3\left(\mathrm{CH}_{2}\right), 24.8$ $\left(\mathrm{CH}_{3}\right), 22.2\left(2 \mathrm{C}, \mathrm{OCHCH}_{3}\right), 17.1\left(\mathrm{CH}_{3}\right), 14.5\left(\mathrm{CH}_{3}\right), 13.2\left(\mathrm{CH}_{3}\right)$; LRMS (+ESI) $\mathrm{m} / z 395.67$ $\left([\mathrm{M}+\mathrm{H}]^{+}, 100 \%\right)$; Anal. $\left(\mathrm{C}_{23} \mathrm{H}_{30} \mathrm{~N}_{4} \mathrm{O}_{2}\right)$ : calcd, $\mathrm{C} 70.02, \mathrm{H} 7.66, \mathrm{~N} 14.20$; found, $\mathrm{C} 71.04, \mathrm{H}$ 7.82, N 14.52 .

\subsubsection{2-(2-(4-Hydroxyphenyl)-5,7-dimethylpyrazolo[1,5-a]pyrimidin-3-yl)- $N, N$ - diethylacetamide (13)}

A cooled $\left(0{ }^{\circ} \mathrm{C}\right)$ solution of $12(1.58 \mathrm{~g}, 4.0 \mathrm{mmol})$ in dichloromethane $(12.5 \mathrm{~mL})$ was treated portionwise with aluminum chloride $(1.76 \mathrm{~g}, 13.0 \mathrm{mmol}, 3.3$ equiv. $)$ and the solution allowed to warm to rt. After several minutes, a heterogeneous mixture formed and was stirred 
vigorously for $20 \mathrm{~h}$. The reaction mixture was cooled $\left(0{ }^{\circ} \mathrm{C}\right)$, treated with half sat. aq. $\mathrm{NH}_{4} \mathrm{Cl}$ $(40 \mathrm{~mL})$, stirred for $0.5 \mathrm{~h}$, then allowed to warm to $\mathrm{rt}$ and stirred a further $2 \mathrm{~h}$. The mixture was filtered and the precipitate washed sequentially with $\mathrm{H}_{2} \mathrm{O}(40 \mathrm{~mL}), \mathrm{CHCl}_{3}(40 \mathrm{~mL})$, and set aside. The filtrate layers were separated and the aqueous phase was extracted with $\mathrm{CHCl}_{3}$ $(2 \times 15 \mathrm{~mL})$. The combined organic phases were washed with $\mathrm{H}_{2} \mathrm{O}(30 \mathrm{~mL})$, brine $\mathrm{H}_{2} \mathrm{O}(30$ $\mathrm{mL})$, dried $\left(\mathrm{MgSO}_{4}\right)$, and the solvent evaporated. The residue thus obtained was combined with the precipitate previously set aside, dissolved in $\mathrm{CHCl}_{3}-\mathrm{MeOH}(50: 50)$ and dry-loaded on silica gel, and eluted through a short plug of silica using $\mathrm{CHCl}_{3}-\mathrm{MeOH}(90: 10)$ as eluent. The solvent was evaporated under reduced pressure and the remaining solid triturated with $\mathrm{Et}_{2} \mathrm{O}$ to give $8(1.21 \mathrm{~g}, 86 \%)$ as a pale yellow crystalline solid of suitable purity for use in the following alkylation reactions (vide infra). Analytical purity was achieved by recrystallization from isopropanol to give colorless crystals. m.p. $247-249{ }^{\circ} \mathrm{C} ; \mathrm{R}_{f} 0.12$ $\left(\mathrm{CHCl}_{3}-\mathrm{MeOH}, 95: 5\right) ;{ }^{1} \mathrm{H}$ NMR $\left(500 \mathrm{MHz}, \mathrm{CDCl}_{3}\right) \delta 7.64(2 \mathrm{H}, \mathrm{d}, J=8.5 \mathrm{~Hz}, \mathrm{ArH}), 7.13$ $(1 \mathrm{H}$, br s, ArOH $), 6.82(2 \mathrm{H}, \mathrm{d}, J=8.5 \mathrm{~Hz}, \mathrm{ArH}), 6.49(1 \mathrm{H}, \mathrm{s}, \mathrm{ArH}), 3.95\left(2 \mathrm{H}, \mathrm{s}, \mathrm{ArCH}_{2}\right), 3.50$ $\left(2 \mathrm{H}, \mathrm{q}, J=7.2 \mathrm{~Hz}, \mathrm{NCH}_{2}\right), 3.38\left(2 \mathrm{H}, \mathrm{q}, J=7.2 \mathrm{~Hz}, \mathrm{NCH}_{2}\right), 2.73\left(3 \mathrm{H}, \mathrm{s}, \mathrm{ArCH}_{3}\right), 2.54(3 \mathrm{H}, \mathrm{s}$, $\left.\mathrm{ArCH}_{3}\right), 1.16\left(3 \mathrm{H}, \mathrm{t}, J=7.2 \mathrm{~Hz}, \mathrm{CH}_{2} \underline{\mathrm{CH}}_{3}\right), 1.09\left(3 \mathrm{H}, \mathrm{t}, J=7.2 \mathrm{~Hz}, \mathrm{CH}_{2} \underline{\mathrm{CH}}_{3}\right) ;{ }^{13} \mathrm{C} \mathrm{NMR}(125$ $\left.\mathrm{MHz}, \mathrm{CDCl}_{3}\right) \delta 170.7(\mathrm{C}=\mathrm{O}), 157.7\left(\mathrm{C}_{\text {quat. }}\right), 157.0\left(\mathrm{C}_{\text {quat. }}\right), 155.6\left(\mathrm{C}_{\text {quat }}\right), 147.7\left(\mathrm{C}_{\text {quat. }}\right), 145.0$ $\left(\mathrm{C}_{\text {quat. }}\right), 130.2(2 \mathrm{C}, \mathrm{CH}), 125.5\left(\mathrm{C}_{\text {quat. }}\right), 115.8(2 \mathrm{C}, \mathrm{CH}), 108.3(\mathrm{CH}), 100.6\left(\mathrm{C}_{\text {quat }}\right), 42.7$ $\left(\mathrm{NCH}_{2}\right), 41.0\left(\mathrm{NCH}_{2}\right), 28.5\left(\mathrm{ArCH}_{2}\right), 24.7\left(\mathrm{ArCH}_{3}\right), 17.1\left(\mathrm{ArCH}_{3}\right), 14.3\left(\mathrm{CH}_{2} \mathrm{CH}_{3}\right), 13.1$ $\left(\mathrm{CH}_{2} \mathrm{CH}_{3}\right)$; LRMS (+ESI) $\mathrm{m} / z 353.53\left([\mathrm{M}+\mathrm{H}]^{+}, 100 \%\right)$; Anal. $\left(\mathrm{C}_{20} \mathrm{H}_{24} \mathrm{~N}_{4} \mathrm{O}_{2}\right)$ : calcd, $\mathrm{C}$ 68.16, $\mathrm{H}$ 6.86, N 15.90; found, $\mathrm{C} 68.33, \mathrm{H}$ 7.23, N 15.72. All physical and spectroscopic data matched those previously reported.[24]

\subsection{General procedure for the alkylation of $\mathbf{1 3}$}

A mixture of 13 (176 mg, $0.5 \mathrm{mmol}, 1$ equiv.), anhydrous $\mathrm{K}_{2} \mathrm{CO}_{3}$ powder ( $346 \mathrm{mg}, 2.5 \mathrm{mmol}$, 5 equiv.), and the appropriate bromoalkane ( $0.75 \mathrm{mmol}, 1.5$ equiv.) in DMF ( $1 \mathrm{~mL})$ was stirred $40{ }^{\circ} \mathrm{C}$ for $14 \mathrm{~h}$. The mixture was poured into $\mathrm{H}_{2} \mathrm{O}(50 \mathrm{~mL})$, and extracted with EtOAc $(3 \times 10 \mathrm{~mL})$. The combined organic layers were washed with brine $(10 \mathrm{~mL})$, dried $\left(\mathrm{MgSO}_{4}\right)$, and the solvent evaporated. The crude products were purified by flash chromatography eluting with $\mathrm{CHCl}_{3}-\mathrm{MeOH}(96: 4)$ or recrystallized from isopropanol.

\subsubsection{2-(2-(4-Isobutoxyphenyl)-5,7-dimethylpyrazolo[1,5-a]pyrimidin-3-yl)- $N, N-$ diethylacetamide (14)}

Treating 13 with 1-bromo-2-methylpropane ( $80 \mu \mathrm{L}, 0.75 \mathrm{mmol}, 1.5$ equiv.) according to the general procedure gave 14 as a colorless crystalline solid $(175 \mathrm{mg}, 86 \%)$. m.p. $116-118{ }^{\circ} \mathrm{C}$; $\mathrm{R}_{f} 0.44\left(\mathrm{CHCl}_{3}-\mathrm{MeOH}, 90: 10\right) ;{ }^{1} \mathrm{H} \mathrm{NMR}\left(500 \mathrm{MHz}, \mathrm{CDCl}_{3}\right) \delta 7.75(2 \mathrm{H}, \mathrm{d}, J=8.5 \mathrm{~Hz}, \mathrm{ArH})$, $6.96(2 \mathrm{H}, \mathrm{d}, J=8.5 \mathrm{~Hz}, \mathrm{ArH}), 6.47(1 \mathrm{H}, \mathrm{s}, \mathrm{ArH}), 3.90\left(2 \mathrm{H}, \mathrm{s}, \mathrm{ArCH}_{2}\right), 3.75(2 \mathrm{H}, \mathrm{d}, J=6.5$ $\left.\mathrm{Hz}, \mathrm{OCH}_{2}\right), 3.49\left(2 \mathrm{H}, \mathrm{q}, J=7.0 \mathrm{~Hz}, \mathrm{NCH}_{2}\right), 3.40\left(2 \mathrm{H}, \mathrm{q}, J=7.0 \mathrm{~Hz}, \mathrm{NCH}_{2}\right), 2.71(3 \mathrm{H}, \mathrm{s}$, $\left.\mathrm{ArCH}_{3}\right), 2.51\left(3 \mathrm{H}, \mathrm{s}, \mathrm{ArCH}_{3}\right), 2.09(1 \mathrm{H}$, app. sep., $J=6.5 \mathrm{~Hz}, \mathrm{CH}), 1.19(3 \mathrm{H}, \mathrm{t}, J=7.0 \mathrm{~Hz}$, $\left.\mathrm{CH}_{2} \mathrm{CH}_{3}\right), 1.10\left(3 \mathrm{H}, \mathrm{t}, J=7.0 \mathrm{~Hz}, \mathrm{CH}_{2} \underline{\mathrm{CH}}_{3}\right), 1.03\left(6 \mathrm{H}, \mathrm{d}, J=6.5 \mathrm{~Hz}, \mathrm{CH}\left(\mathrm{CH}_{3}\right)_{2}\right) ;{ }^{13} \mathrm{C} \mathrm{NMR}$ $\left(125 \mathrm{MHz}, \mathrm{CDCl}_{3}\right) \delta 170.2(\mathrm{C}=\mathrm{O}), 159.6\left(\mathrm{C}_{\text {quat. }}\right), 157.4\left(\mathrm{C}_{\text {quat. }}\right), 155.2\left(\mathrm{C}_{\text {quat. }}\right), 147.7\left(\mathrm{C}_{\text {quat. }}\right)$, $144.8\left(\mathrm{C}_{\text {quat. }}\right), 130.0(2 \mathrm{C}, \mathrm{CH}), 126.2\left(\mathrm{C}_{\text {quat. }}\right), 114.7(2 \mathrm{C}, \mathrm{CH}), 108.1\left(\mathrm{C}_{\text {quat. }}\right), 100.8\left(\mathrm{C}_{\text {quat. }}\right)$, $74.5\left(\mathrm{OCH}_{2}\right), 42.4\left(\mathrm{NCH}_{2}\right), 40.7\left(\mathrm{NCH}_{2}\right), 28.35\left(\mathrm{CH}_{2}\right), 28.28(\mathrm{CH}), 24.7\left(\mathrm{CH}_{3}\right), 19.3(2 \mathrm{C}$, $\left.\mathrm{CH}\left(\mathrm{CH}_{3}\right)_{2}\right), 17.0\left(\mathrm{CH}_{3}\right), 14.4\left(\mathrm{CH}_{3}\right), 13.2\left(\mathrm{CH}_{3}\right)$; LRMS (+ESI) $\mathrm{m} / z 409.07\left([\mathrm{M}+\mathrm{H}]^{+}\right.$, $100 \%)$; Anal. $\left(\mathrm{C}_{24} \mathrm{H}_{32} \mathrm{~N}_{4} \mathrm{O}_{2}\right)$ : calcd, $\mathrm{C} 70.56, \mathrm{H} 7.90, \mathrm{~N} 13.71$; found, $\mathrm{C} 70.55, \mathrm{H} 8.10, \mathrm{~N}$ 13.71 . 


\subsubsection{2-(2-(4-Cyclobutoxyphenyl)-5,7-dimethylpyrazolo[1,5-a]pyrimidin-3-yl)- $N, N-$ diethylacetamide (15)}

Treating 13 with bromocyclobutane ( $70 \mu \mathrm{L}, 0.75 \mathrm{mmol}, 1.5$ equiv.) for 5 days according to the general procedure gave 15 as a colorless crystalline solid (135 mg, 66\%, 82\% brsm). m.p. 157-159 ${ }^{\circ} \mathrm{C} ; \mathrm{R}_{f} 0.54\left(\mathrm{CHCl}_{3}-\mathrm{MeOH}, 90: 10\right) ;{ }^{1} \mathrm{H} \mathrm{NMR}\left(500 \mathrm{MHz}, \mathrm{CDCl}_{3}\right) \delta 7.72(2 \mathrm{H}, \mathrm{d}, J=$ $9.0 \mathrm{~Hz}, \mathrm{ArH}), 6.89(2 \mathrm{H}, \mathrm{d}, J=9.0 \mathrm{~Hz}, \mathrm{ArH}), 6.52(1 \mathrm{H}, \mathrm{s}, \mathrm{ArH}), 4.69(1 \mathrm{H}$, quin., $J=7.3 \mathrm{~Hz}$, $\mathrm{OCH}), 3.99\left(2 \mathrm{H}, \mathrm{s}, \mathrm{ArCH}_{2}\right), 3.51\left(2 \mathrm{H}, \mathrm{q}, J=7.3 \mathrm{~Hz}, \mathrm{NCH}_{2}\right), 3.41\left(2 \mathrm{H}, \mathrm{q}, J=7.3 \mathrm{~Hz}, \mathrm{NCH}_{2}\right)$, $2.77\left(3 \mathrm{H}, \mathrm{s}, \mathrm{ArCH}_{3}\right), 2.60\left(3 \mathrm{H}, \mathrm{s}, \mathrm{ArCH}_{3}\right), 2.50-2.44\left(2 \mathrm{H}, \mathrm{m}, \mathrm{CHCH}_{2}\right), 2.23-2.15(2 \mathrm{H}, \mathrm{m}$, $\left.\mathrm{CHC}_{2}\right), 1.91-1.84\left(1 \mathrm{H}, \mathrm{m}, \mathrm{CHCH}_{2} \underline{\mathrm{C}}_{2}\right), 1.75-1.67\left(1 \mathrm{H}, \mathrm{m}, \mathrm{CHCH}_{2} \underline{\mathrm{C}}_{2}\right), 1.22(3 \mathrm{H}, \mathrm{t}, J=$ $\left.7.3 \mathrm{~Hz}, \mathrm{CH}_{2} \mathrm{CH}_{3}\right), 1.12\left(3 \mathrm{H}, \mathrm{t}, J=7.3 \mathrm{~Hz}, \mathrm{CH}_{2} \mathrm{CH}_{3}\right) ;{ }^{13} \mathrm{C} \mathrm{NMR}\left(125 \mathrm{MHz}, \mathrm{CDCl}_{3}\right) \delta 170.0$ $(\mathrm{C}=\mathrm{O}), 157.9\left(\mathrm{C}_{\text {quat. }}\right), 157.5\left(\mathrm{C}_{\text {quat. }}\right), 155.3\left(\mathrm{C}_{\text {quat. }}\right), 147.8\left(\mathrm{C}_{\text {quat. }}\right), 144.8\left(\mathrm{C}_{\text {quat }}\right), 130.1(2 \mathrm{C}$, $\mathrm{CH}), 126.4\left(\mathrm{C}_{\text {quat. }}\right), 115.2(2 \mathrm{C}, \mathrm{CH}), 108.2(\mathrm{CH}), 100.9\left(\mathrm{C}_{\text {quat. }}\right), 71.6(\mathrm{OCH}), 42.4\left(\mathrm{NCH}_{2}\right)$, $40.7\left(\mathrm{NCH}_{2}\right), 30.8\left(2 \mathrm{C}, \mathrm{CH}_{2}\right), 28.3\left(\mathrm{CH}_{2}\right), 24.8\left(\mathrm{CH}_{3}\right), 17.0\left(\mathrm{CH}_{3}\right), 14.5\left(\mathrm{CH}_{3}\right), 13.4\left(\mathrm{CH}_{2}\right)$, $13.2\left(\mathrm{CH}_{3}\right)$; LRMS (+ESI) $\mathrm{m} / z 407.07\left([\mathrm{M}+\mathrm{H}]^{+}, 100 \%\right)$; Anal. $\left(\mathrm{C}_{24} \mathrm{H}_{30} \mathrm{~N}_{4} \mathrm{O}_{2}\right)$ : calcd, $\mathrm{C}$ 70.91, H 7.44, N 13.78; found, C 70.95, H 7.54, N 13.85.

\subsubsection{2-(2-(4-Cyclopentyloxyphenyl)-5,7-dimethylpyrazolo[1,5-a]pyrimidin-3-yl)- $N, N-$ diethylacetamide (16)}

Treating 13 with bromocyclopentane $\left(80 \mu \mathrm{L}, 0.75 \mathrm{mmol}, 1.5\right.$ equiv.) for 5 days at $45{ }^{\circ} \mathrm{C}$ according to the general procedure gave $\mathbf{1 6}$ as a colorless crystalline solid (198 $\mathrm{mg}, 47 \%$ ). m.p. $130-132{ }^{\circ} \mathrm{C} ; \mathrm{R}_{f} 0.42\left(\mathrm{CHCl}_{3}-\mathrm{MeOH}, 90: 10\right) ;{ }^{1} \mathrm{H} \mathrm{NMR}\left(500 \mathrm{MHz}, \mathrm{CDCl}_{3}\right) \delta 7.73(2 \mathrm{H}, \mathrm{d}$, $J=9.0 \mathrm{~Hz}, \mathrm{ArH}), 6.94(2 \mathrm{H}, \mathrm{d}, J=9.0 \mathrm{~Hz}, \mathrm{ArH}), 6.47(1 \mathrm{H}, \mathrm{s}, \mathrm{ArH}), 4.80(1 \mathrm{H}$, sep., $J=2.9$ $\mathrm{Hz}, \mathrm{OCH}), 3.90\left(2 \mathrm{H}, \mathrm{s}, \mathrm{ArCH}_{2}\right), 3.49\left(2 \mathrm{H}, \mathrm{q}, J=7.2 \mathrm{~Hz}, \mathrm{NCH}_{2}\right), 3.40(2 \mathrm{H}, \mathrm{q}, J=7.2 \mathrm{~Hz}$, $\left.\mathrm{NCH}_{2}\right), 2.72\left(3 \mathrm{H}, \mathrm{s}, \mathrm{ArCH}_{3}\right), 2.52\left(3 \mathrm{H}, \mathrm{s}, \mathrm{ArCH}_{3}\right), 1.95-1.76(6 \mathrm{H}, \mathrm{m}), 1.65-1.57(2 \mathrm{H}, \mathrm{m})$, $1.19\left(3 \mathrm{H}, \mathrm{t}, J=7.2 \mathrm{~Hz}, \mathrm{CH}_{2} \underline{\mathrm{C}}_{3}\right), 1.10\left(3 \mathrm{H}, \mathrm{t}, J=7.2 \mathrm{~Hz}, \mathrm{CH}_{2} \underline{\mathrm{C}}_{3}\right) ;{ }^{13} \mathrm{C}$ NMR $(125 \mathrm{MHz}$, $\left.\mathrm{CDCl}_{3}\right) \delta 170.2(\mathrm{C}=\mathrm{O}), 158.5\left(\mathrm{C}_{\text {quat. }}\right), 157.5\left(\mathrm{C}_{\text {quat. }}\right), 155.3\left(\mathrm{C}_{\text {quat. }}\right), 147.7\left(\mathrm{C}_{\text {quat. }}\right), 144.8\left(\mathrm{C}_{\text {quat. }}\right)$, $130.1(2 \mathrm{C}, \mathrm{CH}), 125.9\left(\mathrm{C}_{\text {quat. }}\right), 115.7(2 \mathrm{C}, \mathrm{CH}), 108.2(\mathrm{CH}), 100.8\left(\mathrm{C}_{\text {quat. }}\right), 79.3(\mathrm{OCH}), 42.4$ $\left(\mathrm{NCH}_{2}\right), 40.7\left(\mathrm{NCH}_{2}\right), 32.9\left(\mathrm{CH}^{2}\right), 28.3\left(\mathrm{CH}_{2}\right), 24.7\left(\mathrm{CH}_{3}\right), 24.1\left(2 \mathrm{C}, \mathrm{OCHCH}{ }_{3}\right), 17.0\left(\mathrm{CH}_{3}\right)$, $14.4\left(\mathrm{CH}_{3}\right), 13.2\left(\mathrm{CH}_{3}\right)$; LRMS (+ESI) $\mathrm{m} / z 421.13\left([\mathrm{M}+\mathrm{H}]^{+}, 100 \%\right)$; Anal. $\left(\mathrm{C}_{25} \mathrm{H}_{32} \mathrm{~N}_{4} \mathrm{O}_{2}\right)$ : calcd, C 71.40, H 7.67, N 13.32; found, C 71.49, H 7.87, N 13.23.

\subsubsection{2-(2-(4-Cyclopropylmethoxyphenyl)-5,7-dimethylpyrazolo[1,5-a]pyrimidin-3-yl)- $N, N$-diethylacetamide (17)}

Treating 13 with (bromomethyl)cyclopropane ( $73 \mu \mathrm{L}, 0.75 \mathrm{mmol}, 1.5$ equiv.) for $20 \mathrm{~h}$ according to the general procedure gave $\mathbf{1 7}$ as a colorless crystalline solid (176 $\mathrm{mg}, 86 \%$ ). m.p. $122-124{ }^{\circ} \mathrm{C} ; \mathrm{R}_{f} 0.38\left(\mathrm{CHCl}_{3}-\mathrm{MeOH}, 90: 10\right) ;{ }^{1} \mathrm{H} \mathrm{NMR}\left(500 \mathrm{MHz}, \mathrm{CDCl}_{3}\right) \delta 7.75(2 \mathrm{H}, \mathrm{d}$, $J=9.0 \mathrm{~Hz}, \mathrm{ArH}), 6.97(2 \mathrm{H}, \mathrm{d}, J=9.0 \mathrm{~Hz}, \mathrm{ArH}), 6.48(1 \mathrm{H}, \mathrm{s}, \mathrm{ArH}), 3.90\left(2 \mathrm{H}, \mathrm{s}, \mathrm{ArCH}_{2}\right), 3.84$ $\left(2 \mathrm{H}, \mathrm{d}, J=7.0 \mathrm{~Hz}, \mathrm{OCH}_{2}\right), 3.49\left(2 \mathrm{H}, \mathrm{q}, J=7.2 \mathrm{~Hz}, \mathrm{NCH}_{2}\right), 3.40\left(2 \mathrm{H}, \mathrm{q}, J=7.2 \mathrm{~Hz}, \mathrm{NCH}_{2}\right)$, $2.73\left(3 \mathrm{H}, \mathrm{s}, \mathrm{ArCH}_{3}\right), 2.53\left(3 \mathrm{H}, \mathrm{s}, \mathrm{ArCH}_{3}\right), 1.30-1.27\left(1 \mathrm{H}, \mathrm{m}, \mathrm{OCH}_{2} \mathrm{C} \underline{\mathrm{H}}\right), 1.19(3 \mathrm{H}, \mathrm{t}, J=7.2$ $\left.\mathrm{Hz}, \mathrm{CH}_{2} \mathrm{CH}_{3}\right), 1.11\left(3 \mathrm{H}, \mathrm{t}, J=7.2 \mathrm{~Hz}, \mathrm{CH}_{2} \underline{\mathrm{CH}}_{3}\right), 0.66-0.63\left(2 \mathrm{H}, \mathrm{m}, \mathrm{CHCH}_{2}\right), 0.38-0.35(2 \mathrm{H}$, $\left.\mathrm{m}, \mathrm{CHC}_{2}\right) ;{ }^{13} \mathrm{C} \mathrm{NMR}\left(125 \mathrm{MHz}, \mathrm{CDCl}_{3}\right) \delta 170.2(\mathrm{C}=\mathrm{O}), 159.4\left(\mathrm{C}_{\text {quat. }}\right), 157.5\left(\mathrm{C}_{\text {quat. }}\right), 155.2$ 
( $\left.\mathrm{C}_{\text {quat. }}\right), 147.8$ ( $\left.\mathrm{C}_{\text {quat. }}\right), 144.8\left(\mathrm{C}_{\text {quat. }}\right), 130.1(2 \mathrm{C}, \mathrm{CH}), 126.4\left(\mathrm{C}_{\text {quat. }}\right), 114.8(2 \mathrm{C}, \mathrm{CH}), 108.2$ $(\mathrm{CH}), 100.9\left(\mathrm{C}_{\text {quat. }}\right), 72.9\left(\mathrm{OCH}_{2}\right), 42.4\left(\mathrm{NCH}_{2}\right), 40.7\left(\mathrm{NCH}_{2}\right), 28.3\left(\mathrm{CH}_{2}\right), 24.7\left(\mathrm{CH}_{3}\right), 17.0$ $\left(\mathrm{CH}_{3}\right), 14.5\left(\mathrm{CH}_{3}\right), 13.2\left(\mathrm{CH}_{3}\right), 10.4\left(\mathrm{OCH}_{2} \underline{\mathrm{CH}}\right), 3.31\left(2 \mathrm{C}, \mathrm{CHCH}_{2}\right) ; \mathrm{LRMS}(+\mathrm{ESI}) \mathrm{m} / \mathrm{z}$ $407.07\left([\mathrm{M}+\mathrm{H}]^{+}, 100 \%\right)$; Anal. $\left(\mathrm{C}_{24} \mathrm{H}_{30} \mathrm{~N}_{4} \mathrm{O}_{2}\right)$ : calcd, C 70.91, $\mathrm{H}$ 7.44, N 13.78; found, $\mathrm{C}$ 70.98, H 7.62, N 13.80 .

\subsubsection{2-(2-(4-Cyclobutylmethoxyphenyl)-5,7-dimethylpyrazolo[1,5-a]pyrimidin-3-yl)- $N, N$-diethylacetamide (18)}

Treating 13 with (bromomethyl)cyclobutane ( $85 \mu \mathrm{L}, 0.75 \mathrm{mmol}, 1.5$ equiv.) according to the general procedure gave 18 as a colorless crystalline solid $\left(189\right.$ g, 90\%). m.p. $107-109{ }^{\circ} \mathrm{C} ; \mathrm{R}_{f}$ $0.47\left(\mathrm{CHCl}_{3}-\mathrm{MeOH}, 90: 10\right) ;{ }^{1} \mathrm{H} \mathrm{NMR}\left(500 \mathrm{MHz}, \mathrm{CDCl}_{3}\right) \delta 7.75(2 \mathrm{H}, \mathrm{d}, J=9.0 \mathrm{~Hz}, \mathrm{ArH})$, $6.97(2 \mathrm{H}, \mathrm{d}, J=9.0 \mathrm{~Hz}, \mathrm{ArH}), 6.49(1 \mathrm{H}, \mathrm{s}, \mathrm{ArH}), 3.97\left(2 \mathrm{H}, \mathrm{d}, J=6.5 \mathrm{~Hz}, \mathrm{OC}_{2}\right), 3.91(2 \mathrm{H}, \mathrm{s}$, $\left.\mathrm{ArCH}_{2}\right), 3.49\left(2 \mathrm{H}, \mathrm{q}, J=7.2 \mathrm{~Hz}, \mathrm{NCH}_{2}\right), 3.41\left(2 \mathrm{H}, \mathrm{q}, J=7.2 \mathrm{~Hz}, \mathrm{NCH}_{2}\right), 2.80-2.77(1 \mathrm{H}, \mathrm{m}$, $\left.\mathrm{OCH}_{2} \mathrm{CH}\right), 2.72\left(3 \mathrm{H}, \mathrm{s}, \mathrm{ArCH}_{3}\right), 2.53\left(3 \mathrm{H}, \mathrm{s}, \mathrm{ArCH}_{3}\right), 2.17-2.13(2 \mathrm{H}, \mathrm{m}$, cyclobutane $), 1.98-$ $1.86\left(2 \mathrm{H}, \mathrm{m}\right.$, cyclobutane), $1.20\left(3 \mathrm{H}, \mathrm{t}, J=7.1 \mathrm{~Hz}, \mathrm{CH}_{2} \mathrm{CH}_{3}\right), 1.11(3 \mathrm{H}, \mathrm{t}, J=7.1 \mathrm{~Hz}$, $\left.\mathrm{CH}_{2} \mathrm{CH}_{3}\right) ;{ }^{13} \mathrm{C}$ NMR $\left(125 \mathrm{MHz}, \mathrm{CDCl}_{3}\right) \delta 170.2(\mathrm{C}=\mathrm{O}), 159.7\left(\mathrm{C}_{\text {quat. }}\right), 157.5\left(\mathrm{C}_{\text {quat. }}\right), 155.2$ $\left(\mathrm{C}_{\text {quat. }}\right), 147.8$ ( $\left.\mathrm{C}_{\text {quat. }}\right), 144.9$ ( $\left.\mathrm{C}_{\text {quat. }}\right), 130.0(2 \mathrm{C}, \mathrm{CH}), 126.3\left(\mathrm{C}_{\text {quat. }}\right), 114.8(2 \mathrm{C}, \mathrm{CH}), 108.2$ $(\mathrm{CH}), 100.9\left(\mathrm{C}_{\text {quat. }}\right), 72.3\left(\mathrm{OCH}_{2}\right), 42.4\left(\mathrm{NCH}_{2}\right), 40.7\left(\mathrm{NCH}_{2}\right), 34.8(\mathrm{CH}), 29.8\left(\mathrm{CH}_{2}\right), 28.3$ $\left(\mathrm{CH}_{2}\right), 25.0\left(2 \mathrm{C}, \mathrm{CH}_{2}\right), 24.7\left(\mathrm{CH}_{3}\right), 18.7\left(\mathrm{CH}_{2}\right), 17.0\left(\mathrm{CH}_{3}\right), 14.5\left(\mathrm{CH}_{3}\right), 13.2\left(\mathrm{CH}_{3}\right)$; LRMS (+ESI) $m / z 421.13\left([\mathrm{M}+\mathrm{H}]^{+}, 100 \%\right)$; Anal. $\left(\mathrm{C}_{25} \mathrm{H}_{32} \mathrm{~N}_{4} \mathrm{O}_{2}\right)$ : calcd, $\mathrm{C} 71.40, \mathrm{H}$ 7.67, N 13.32; found, C 71.46, H 7.62, N 13.27.

\subsubsection{2-(2-(4-Cyclopentylmethoxyphenyl)-5,7-dimethylpyrazolo[1,5-a]pyrimidin-3-yl)- $N, N$-diethylacetamide (19)}

Treating 13 with (iodomethyl)cyclopentane $\left(100 \mu \mathrm{L}, 0.75 \mathrm{mmol}, 1.5\right.$ equiv.) at $50{ }^{\circ} \mathrm{C}$ for 5 days according to the general procedure gave 19 as a colorless crystalline solid ( $84 \mathrm{mg}, 37 \%$, $78 \%$ brsm). m.p. $107-108{ }^{\circ} \mathrm{C} ; \mathrm{R}_{f} 0.45\left(\mathrm{CHCl}_{3}-\mathrm{MeOH}, 90: 10\right) ;{ }^{1} \mathrm{H}$ NMR $\left(500 \mathrm{MHz}, \mathrm{CDCl}_{3}\right) \delta$ $7.74(2 \mathrm{H}, \mathrm{d}, J=9.0 \mathrm{~Hz}, \operatorname{ArH}), 6.97(2 \mathrm{H}, \mathrm{d}, J=9.0 \mathrm{~Hz}, \operatorname{ArH}), 6.49(1 \mathrm{H}, \mathrm{s}, \operatorname{ArH}), 3.91(2 \mathrm{H}, \mathrm{s}$, $\left.\mathrm{ArCH}_{2}\right), 3.87\left(2 \mathrm{H}, \mathrm{d}, J=7.0 \mathrm{~Hz}, \mathrm{OCH}_{2}\right), 3.49\left(2 \mathrm{H}, \mathrm{q}, J=7.2 \mathrm{~Hz}, \mathrm{NCH}_{2}\right), 3.41(2 \mathrm{H}, \mathrm{q}, J=$ $\left.7.2 \mathrm{~Hz}, \mathrm{NCH}_{2}\right), 2.73\left(3 \mathrm{H}, \mathrm{s}, \mathrm{ArCH}_{3}\right), 2.53\left(3 \mathrm{H}, \mathrm{s}, \mathrm{ArCH}_{3}\right), 2.42-2.33\left(1 \mathrm{H}, \mathrm{m}, \mathrm{OCH}_{2} \mathrm{C}\right.$ 1.88-1.82 (2H, m), 1.68-1.56 (4H, m), 1.41-1.34 (2H, m), $1.20\left(3 \mathrm{H}, \mathrm{t}, J=7.0 \mathrm{~Hz}, \mathrm{CH}_{2} \mathrm{CH}_{3}\right)$, $1.11\left(3 \mathrm{H}, \mathrm{t}, J=7.0 \mathrm{~Hz}, \mathrm{CH}_{2} \mathrm{CH}_{3}\right) ;{ }^{13} \mathrm{C} \mathrm{NMR}\left(125 \mathrm{MHz}, \mathrm{CDCl}_{3}\right) \delta 170.3(\mathrm{C}=\mathrm{O}), 159.7\left(\mathrm{C}_{\text {quat. }}\right)$, 157.5 ( $\left.\mathrm{C}_{\text {quat. }}\right), 155.3\left(\mathrm{C}_{\text {quat. }}\right), 147.8\left(\mathrm{C}_{\text {quat. }}\right), 144.9\left(\mathrm{C}_{\text {quat. }}\right), 130.0(2 \mathrm{C}, \mathrm{CH}), 126.2\left(\mathrm{C}_{\text {quat. }}\right), 114.8$ $(2 \mathrm{C}, \mathrm{CH}), 108.2(\mathrm{CH}), 100.9\left(\mathrm{C}_{\text {quat. }}\right), 72.5\left(\mathrm{OCH}_{2}\right), 42.4\left(\mathrm{NCH}_{2}\right), 40.7\left(\mathrm{NCH}_{2}\right), 39.2(\mathrm{CH})$, $29.6\left(2 \mathrm{C}, \mathrm{CH}_{2}\right), 28.3\left(\mathrm{CH}_{2}\right), 25.6\left(2 \mathrm{C}, \mathrm{CH}_{2}\right), 24.7\left(\mathrm{CH}_{3}\right), 17.1\left(\mathrm{CH}_{3}\right), 14.5\left(\mathrm{CH}_{3}\right), 13.2\left(\mathrm{CH}_{3}\right)$; LRMS (+ESI) $m / z 435.07\left([\mathrm{M}+\mathrm{H}]^{+}, 100 \%\right)$; Anal. $\left(\mathrm{C}_{26} \mathrm{H}_{34} \mathrm{~N}_{4} \mathrm{O}_{2}\right)$ : calcd, C 71.86, H 7.89, $\mathrm{N}$ 12.89; found, C 71.46, H 7.62, N 13.27.

\subsubsection{2-(2-(4-Cyclohexylmethoxyphenyl)-5,7-dimethylpyrazolo[1,5-a]pyrimidin-3-yl)- $\mathrm{N}, \mathrm{N}$-diethylacetamide (20)}

Treating 13 with (bromomethyl)cyclohexane (105 $\mu \mathrm{L}, 0.75 \mathrm{mmol}, 1.5$ equiv.) according to the general procedure gave 20 as a colorless crystalline solid (193 mg, 86\%). m.p. 141-143 ${ }^{\circ} \mathrm{C} ; \mathrm{R}_{f} 0.42\left(\mathrm{CHCl}_{3}-\mathrm{MeOH}, 90: 10\right) ;{ }^{1} \mathrm{H} \mathrm{NMR}\left(500 \mathrm{MHz}, \mathrm{CDCl}_{3}\right) \delta 7.74(2 \mathrm{H}, \mathrm{d}, J=8.5 \mathrm{~Hz}$, $\mathrm{ArH}), 6.96(2 \mathrm{H}, \mathrm{d}, J=8.5 \mathrm{~Hz}, \mathrm{ArH}), 6.49(1 \mathrm{H}, \mathrm{s}, \mathrm{ArH}), 3.92\left(2 \mathrm{H}, \mathrm{s}, \mathrm{ArCH}_{2}\right), 3.79(2 \mathrm{H}, \mathrm{d}, J=$ 
$\left.6.5 \mathrm{~Hz}, \mathrm{OCH}_{2}\right), 3.49\left(2 \mathrm{H}, \mathrm{q}, J=7.0 \mathrm{~Hz}, \mathrm{NCH}_{2}\right), 3.41\left(2 \mathrm{H}, \mathrm{q}, J=7.2 \mathrm{~Hz}, \mathrm{NCH}_{2}\right), 2.73(3 \mathrm{H}, \mathrm{s}$, $\left.\mathrm{ArCH}_{3}\right), 2.54\left(3 \mathrm{H}, \mathrm{s}, \mathrm{ArCH}_{3}\right), 1.89-1.69(6 \mathrm{H}, \mathrm{m}), 1.34-1.22(3 \mathrm{H}, \mathrm{m}), 1.20(3 \mathrm{H}, \mathrm{t}, J=7.0 \mathrm{~Hz}$, $\left.\mathrm{CH}_{2} \mathrm{CH}_{3}\right), 1.11\left(3 \mathrm{H}, \mathrm{t}, J=7.0 \mathrm{~Hz}, \mathrm{CH}_{2} \mathrm{CH}_{3}\right), 1.10-1.02(2 \mathrm{H}, \mathrm{m}) ;{ }^{13} \mathrm{C}$ NMR $\left(125 \mathrm{MHz}, \mathrm{CDCl}_{3}\right)$ $\delta 170.2(\mathrm{C}=\mathrm{O}), 159.7\left(\mathrm{C}_{\text {quat. }}\right), 157.5\left(\mathrm{C}_{\text {quat. }}\right), 155.3\left(\mathrm{C}_{\text {quat. }}\right), 147.6\left(\mathrm{C}_{\text {quat }}\right), 145.0\left(\mathrm{C}_{\text {quat. }}\right), 130.0$ $(2 \mathrm{C}, \mathrm{CH}), 126.1\left(\mathrm{C}_{\text {quat. }}\right), 114.7(2 \mathrm{C}, \mathrm{CH}), 108.2(\mathrm{CH}), 100.9\left(\mathrm{C}_{\text {quat. }}\right), 73.7\left(\mathrm{OCH}_{2}\right), 42.4$ $\left(\mathrm{NCH}_{2}\right), 40.7\left(\mathrm{NCH}_{2}\right), 37.8(\mathrm{CH}), 30.1\left(2 \mathrm{C}, \mathrm{CH}_{2}\right), 28.3\left(\mathrm{CH}_{2}\right), 26.7\left(\mathrm{CH}_{2}\right), 26.0\left(2 \mathrm{C}, \mathrm{CH}_{2}\right)$, $24.6\left(\mathrm{CH}_{3}\right), 17.1\left(\mathrm{CH}_{3}\right), 14.5\left(\mathrm{CH}_{3}\right), 13.2\left(\mathrm{CH}_{3}\right)$; LRMS (+ESI) $\mathrm{m} / z 449.13\left([\mathrm{M}+\mathrm{H}]^{+}\right.$, $100 \%)$; Anal. $\left(\mathrm{C}_{27} \mathrm{H}_{36} \mathrm{~N}_{4} \mathrm{O}_{2}\right)$ : calcd, $\mathrm{C} 72.29, \mathrm{H} 8.09, \mathrm{~N} \mathrm{12.49}$; found, $\mathrm{C} 72.38, \mathrm{H} 8.32, \mathrm{~N}$ 12.43 .

\subsubsection{2-(2-(4-(Benzyl)oxyphenyl)-5,7-dimethylpyrazolo[1,5-a]pyrimidin-3-yl)- $N, N$ - diethylacetamide (21)}

Treating 13 with benzyl bromide ( $90 \mu \mathrm{L}, 0.75 \mathrm{mmol}, 1.5$ equiv.) according to the general procedure gave 21 as a colorless crystalline solid (191 mg, 86\%). m.p. $151-153{ }^{\circ} \mathrm{C} ; \mathrm{R}_{f} 0.50$ $\left(\mathrm{CHCl}_{3}-\mathrm{MeOH}, 90: 10\right) ;{ }^{1} \mathrm{H}$ NMR $\left(500 \mathrm{MHz}, \mathrm{CDCl}_{3}\right) \delta 7.78(2 \mathrm{H}, \mathrm{d}, J=8.5 \mathrm{~Hz}, \mathrm{ArH}), 7.45$ $(2 \mathrm{H}, \mathrm{d}, J=7.5 \mathrm{~Hz}, \mathrm{ArH}), 7.40-7.37(2 \mathrm{H}, \mathrm{m}, \mathrm{ArH}), 7.34-7.31(1 \mathrm{H}, \mathrm{m}, \mathrm{ArH}), 7.05(2 \mathrm{H}, \mathrm{d}, J=$ $8.5 \mathrm{~Hz}, \mathrm{ArH}), 6.50(1 \mathrm{H}, \mathrm{s}, \mathrm{ArH}), 5.12\left(2 \mathrm{H}, \mathrm{s}, \mathrm{OCH}_{2}\right), 3.91\left(2 \mathrm{H}, \mathrm{s}, \mathrm{ArCH}_{2}\right), 3.50(2 \mathrm{H}, \mathrm{q}, J=$ $\left.7.2 \mathrm{~Hz}, \mathrm{NCH}_{2}\right), 3.40\left(2 \mathrm{H}, \mathrm{q}, J=7.2 \mathrm{~Hz}, \mathrm{NCH}_{2}\right), 2.74\left(3 \mathrm{H}, \mathrm{s}, \mathrm{ArCH}_{3}\right), 2.54\left(3 \mathrm{H}, \mathrm{s}, \mathrm{ArCH}_{3}\right)$, $1.19\left(3 \mathrm{H}, \mathrm{t}, J=7.2 \mathrm{~Hz}, \mathrm{CH}_{2} \underline{\mathrm{C}}_{3}\right), 1.11\left(3 \mathrm{H}, \mathrm{t}, J=7.2 \mathrm{~Hz}, \mathrm{CH}_{2} \underline{\mathrm{C}}_{3}\right) ;{ }^{13} \mathrm{C}$ NMR $(125 \mathrm{MHz}$, $\left.\mathrm{CDCl}_{3}\right) \delta 170.3(\mathrm{C}=\mathrm{O}), 159.2\left(\mathrm{C}_{\text {quat. }}\right), 157.6\left(\mathrm{C}_{\text {quat. }}\right), 155.2\left(\mathrm{C}_{\text {quat }}\right), 147.9\left(\mathrm{C}_{\text {quat. }}\right), 144.8\left(\mathrm{C}_{\text {quat. }}\right)$, $137.1\left(\mathrm{C}_{\text {quat. }}\right), 130.2(2 \mathrm{C}, \mathrm{CH}), 128.7(2 \mathrm{C}, \mathrm{CH}), 128.1(\mathrm{CH}), 127.6(2 \mathrm{C}, \mathrm{CH}), 126.8\left(\mathrm{C}_{\text {quat. }}\right)$, $115.1(2 \mathrm{C}, \mathrm{CH}), 108.3(\mathrm{CH}), 101.0\left(\mathrm{C}_{\text {quat }}\right), 70.2\left(\mathrm{OCH}_{2}\right), 42.5\left(\mathrm{NCH}_{2}\right), 40.7\left(\mathrm{NCH}_{2}\right), 28.3$ $\left(\mathrm{CH}_{2}\right), 24.8\left(\mathrm{CH}_{3}\right), 17.1\left(\mathrm{CH}_{3}\right), 14.5\left(\mathrm{CH}_{3}\right), 13.2\left(\mathrm{CH}_{3}\right)$; LRMS $(+\mathrm{ESI}) \mathrm{m} / \mathrm{z} 443.07\left([\mathrm{M}+\mathrm{H}]^{+}\right.$, $100 \%$ ); Anal. $\left(\mathrm{C}_{27} \mathrm{H}_{30} \mathrm{~N}_{4} \mathrm{O}_{2}\right)$ : calcd, $\mathrm{C} 73.28, \mathrm{H} \mathrm{6.83,} \mathrm{N} \mathrm{12.66;} \mathrm{found,} \mathrm{C} 73.28, \mathrm{H} 6.82, \mathrm{~N}$ 12.61 .

\subsubsection{2-(2-(4-((2-Fluorobenzyl)oxy)phenyl)-5,7-dimethylpyrazolo[1,5-a]pyrimidin-3- yl)- $N, N$-diethylacetamide (22)}

Treating 13 with 2-fluorobenzyl bromide ( $90 \mu \mathrm{L}, 0.75 \mathrm{mmol}, 1.5$ equiv.) according to the general procedure gave 22 as a colorless crystalline solid $(208 \mathrm{mg}, 90 \%)$. m.p. $146-148{ }^{\circ} \mathrm{C}$; $\mathrm{R}_{f} 0.49\left(\mathrm{CHCl}_{3}-\mathrm{MeOH}, 90: 10\right) ;{ }^{1} \mathrm{H} \mathrm{NMR}\left(400 \mathrm{MHz}, \mathrm{CDCl}_{3}\right) \delta 7.78(2 \mathrm{H}, \mathrm{d}, J=8.8 \mathrm{~Hz}, \mathrm{ArH})$, $7.51(1 \mathrm{H}, \mathrm{td}, J=7.4,1.2 \mathrm{~Hz}, \mathrm{ArH}), 7.32-7.28(1 \mathrm{H}, \mathrm{m}, \mathrm{ArH}), 7.16(1 \mathrm{H}, \mathrm{td}, J=7.4,1.2 \mathrm{~Hz}$, ArH), 7.11-7.05 (1H, m, ArH), $7.06(2 \mathrm{H}, \mathrm{d}, J=8.5 \mathrm{~Hz}, \mathrm{ArH}), 6.49(1 \mathrm{H}, \mathrm{s}, \operatorname{ArH}), 5.19(2 \mathrm{H}, \mathrm{s}$, $\left.\mathrm{OCH}_{2}\right), 3.91\left(2 \mathrm{H}, \mathrm{s}, \mathrm{ArCH}_{2}\right), 3.50\left(2 \mathrm{H}, \mathrm{q}, J=7.2 \mathrm{~Hz}, \mathrm{NCH}_{2}\right), 3.40\left(2 \mathrm{H}, \mathrm{q}, J=7.2 \mathrm{~Hz}, \mathrm{NCH}_{2}\right)$, $2.73\left(3 \mathrm{H}, \mathrm{s}, \mathrm{ArCH}_{3}\right), 2.53\left(3 \mathrm{H}, \mathrm{s}, \mathrm{ArCH}_{3}\right), 1.19\left(3 \mathrm{H}, \mathrm{t}, J=7.2 \mathrm{~Hz}, \mathrm{CH}_{2} \underline{\mathrm{C}}_{3}\right), 1.11(3 \mathrm{H}, \mathrm{t}, J=$ $\left.7.2 \mathrm{~Hz}, \mathrm{CH}_{2} \mathrm{CH}_{3}\right) ;{ }^{13} \mathrm{C} \mathrm{NMR}\left(100 \mathrm{MHz}, \mathrm{CDCl}_{3}\right) \delta 170.2(\mathrm{C}=\mathrm{O}), 160.6\left(\mathrm{~d},{ }^{1} J_{\mathrm{CF}}=247.0 \mathrm{~Hz}\right.$, $\left.\mathrm{C}_{\text {quat. }}\right), 158.8\left(\mathrm{C}_{\text {quat. }}\right), 157.6\left(\mathrm{C}_{\text {quat. }}\right), 155.1\left(\mathrm{C}_{\text {quat. }}\right), 147.8\left(\mathrm{C}_{\text {quat. }}\right), 144.8\left(\mathrm{C}_{\text {quat. }}\right), 130.2(2 \mathrm{C}$, $\mathrm{CH}), 129.8(\mathrm{CH}), 129.7\left(\mathrm{~d},{ }^{3} J_{\mathrm{CF}}=5.2 \mathrm{~Hz}, \mathrm{CH}\right), 127.0\left(\mathrm{C}_{\text {quat. }}\right), 124.4\left(\mathrm{~d},{ }^{4} J_{\mathrm{CF}}=3.6 \mathrm{~Hz}, \mathrm{CH}\right)$, $124.2\left(\mathrm{C}_{\text {quat. }}\right), 115.4\left(\mathrm{~d},{ }^{2} J_{\mathrm{CF}}=21.0 \mathrm{~Hz}, \mathrm{CH}\right), 115.0(2 \mathrm{C}, \mathrm{CH}), 108.3(\mathrm{CH}), 101.0\left(\mathrm{C}_{\text {quat. }}\right), 63.8$ $\left(\mathrm{d},{ }^{3} J_{\mathrm{CF}}=4.5 \mathrm{~Hz}, \mathrm{OCH}_{2}\right), 42.4\left(\mathrm{NCH}_{2}\right), 40.7\left(\mathrm{NCH}_{2}\right), 28.2\left(\mathrm{CH}_{2}\right), 24.7\left(\mathrm{CH}_{3}\right), 17.0\left(\mathrm{CH}_{3}\right)$, $14.5\left(\mathrm{CH}_{3}\right)$, $13.2\left(\mathrm{CH}_{3}\right)$; LRMS (+ESI) $\mathrm{m} / z 461.07\left([\mathrm{M}+\mathrm{H}]^{+}, 100 \%\right)$; Anal. $\left(\mathrm{C}_{27} \mathrm{H}_{29} \mathrm{~N}_{4} \mathrm{O}_{2} \mathrm{~F}\right)$ : calcd, C 70.41, H 6.35, N 12.17; found, C 70.42, H 6.45, N 12.11.

5.2.10. 2-(2-(4-((3-Fluorobenzyl)oxy)phenyl)-5,7-dimethylpyrazolo[1,5-a]pyrimidin-3yl)- $N, N$-diethylacetamide (23) 
Treating 13 with 3 -fluorobenzyl bromide ( $90 \mu \mathrm{L}, 0.75 \mathrm{mmol}, 1.5$ equiv.) according to the general procedure gave $\mathbf{2 3}$ as a colorless crystalline solid $(189 \mathrm{mg}, 82 \%)$. m.p. $151-153{ }^{\circ} \mathrm{C}$; $\mathrm{R}_{f} 0.53\left(\mathrm{CHCl}_{3}-\mathrm{MeOH}, 90: 10\right) ;{ }^{1} \mathrm{H} \mathrm{NMR}\left(400 \mathrm{MHz}, \mathrm{CDCl}_{3}\right) \delta 7.79(2 \mathrm{H}, \mathrm{d}, J=8.8 \mathrm{~Hz}, \mathrm{ArH})$, 7.37-7.31 (1H, m, ArH), 7.21-7.16 (2H, m, ArH), $7.04(2 \mathrm{H}, \mathrm{d}, J=8.8 \mathrm{~Hz}, \mathrm{ArH}), 6.99(1 \mathrm{H}$, dd, $J=8.4,2.0 \mathrm{~Hz}, \mathrm{ArH}), 6.49(1 \mathrm{H}, \mathrm{s}, \mathrm{ArH}), 5.11\left(2 \mathrm{H}, \mathrm{s}, \mathrm{OCH}_{2}\right), 3.91\left(2 \mathrm{H}, \mathrm{s}, \mathrm{ArCH}_{2}\right), 3.50$ $\left(2 \mathrm{H}, \mathrm{q}, J=7.1 \mathrm{~Hz}, \mathrm{NCH}_{2}\right), 3.40\left(2 \mathrm{H}, \mathrm{q}, J=7.1 \mathrm{~Hz}, \mathrm{NCH}_{2}\right), 2.73\left(3 \mathrm{H}, \mathrm{s}, \mathrm{ArCH}_{3}\right), 2.53(3 \mathrm{H}, \mathrm{s}$, $\left.\mathrm{ArCH}_{3}\right), 1.19\left(3 \mathrm{H}, \mathrm{t}, J=7.2 \mathrm{~Hz}, \mathrm{CH}_{2} \mathrm{CH}_{3}\right), 1.11\left(3 \mathrm{H}, \mathrm{t}, J=7.2 \mathrm{~Hz}, \mathrm{CH}_{2} \mathrm{CH}_{3}\right) ;{ }^{13} \mathrm{C} \mathrm{NMR}(100$ $\left.\mathrm{MHz}, \mathrm{CDCl}_{3}\right) \delta 170.2(\mathrm{C}=\mathrm{O}), 163.1\left(\mathrm{~d},{ }^{1} J_{\mathrm{CF}}=246.2 \mathrm{~Hz}, \mathrm{C}_{\text {quat. }}\right), 158.8\left(\mathrm{C}_{\text {quat. }}\right), 157.6\left(\mathrm{C}_{\text {quat. }}\right)$, $155.0\left(\mathrm{C}_{\text {quat. }}\right), 147.8\left(\mathrm{C}_{\text {quat. }}\right), 144.8\left(\mathrm{C}_{\text {quat. }}\right), 139.8\left(\mathrm{~d},{ }^{3} J_{\mathrm{CF}}=7.2 \mathrm{~Hz}, \mathrm{C}_{\text {quat. }}\right), 130.3\left(\mathrm{~d},{ }^{3} J_{\mathrm{CF}}=8.1\right.$ $\mathrm{Hz}, \mathrm{CH}), 130.2(2 \mathrm{C}, \mathrm{CH}), 127.0\left(\mathrm{C}_{\text {quat }}\right), 122.8\left(\mathrm{~d},{ }^{4} J_{\mathrm{CF}}=2.9 \mathrm{~Hz}, \mathrm{CH}\right), 115.0(2 \mathrm{C}, \mathrm{CH}), 114.9$ $\left(\mathrm{d},{ }^{2} J_{\mathrm{CF}}=21.1 \mathrm{~Hz}, \mathrm{CH}\right), 114.3\left(\mathrm{~d},{ }^{2} J_{\mathrm{CF}}=22.1 \mathrm{~Hz}, \mathrm{CH}\right), 108.3(\mathrm{CH}), 101.0\left(\mathrm{C}_{\text {quat. }}\right), 69.3(\mathrm{~d}$, $\left.{ }^{4} J_{\mathrm{CF}}=1.8 \mathrm{~Hz}, \mathrm{OCH}_{2}\right), 42.4\left(\mathrm{NCH}_{2}\right), 40.7\left(\mathrm{NCH}_{2}\right), 28.3\left(\mathrm{CH}_{2}\right), 24.7\left(\mathrm{CH}_{3}\right), 17.0\left(\mathrm{CH}_{3}\right), 14.4$ $\left(\mathrm{CH}_{3}\right), 13.2\left(\mathrm{CH}_{3}\right)$; LRMS (+ESI) $\mathrm{m} / z 461.07\left([\mathrm{M}+\mathrm{H}]^{+}, 100 \%\right)$; Anal. $\left(\mathrm{C}_{27} \mathrm{H}_{29} \mathrm{~N}_{4} \mathrm{O}_{2} \mathrm{~F}\right)$ : calcd, C 70.41, H 6.35, N 12.17; found, C 70.50, H 6.12, N 12.00.

\subsubsection{2-(2-(4-((4-Fluorobenzyl)oxy)phenyl)-5,7-dimethylpyrazolo[1,5-a]pyrimidin-3- yl)- $N, N$-diethylacetamide (24)}

Treating 13 with 4-fluorobenzyl bromide ( $95 \mu \mathrm{L}, 0.75 \mathrm{mmol}, 1.5$ equiv.) according to the general procedure gave $\mathbf{2 4}$ as a colorless crystalline solid (186 mg, 81\%). m.p. 104-106 ${ }^{\circ} \mathrm{C}$; $\mathrm{R}_{f} 0.44\left(\mathrm{CHCl}_{3}-\mathrm{MeOH}, 90: 10\right) ;{ }^{1} \mathrm{H}$ NMR $\left(400 \mathrm{MHz} \mathrm{CDCl}_{3}\right) \delta 7.78(2 \mathrm{H}, \mathrm{d}, J=8.4 \mathrm{~Hz}, \mathrm{ArH})$, 7.43-7.40 (2H, m, ArH), 7.09-7.02 (4H, m, ArH), $6.49(1 \mathrm{H}, \mathrm{s}, \mathrm{ArH}), 5.07\left(2 \mathrm{H}, \mathrm{s}, \mathrm{OCH}_{2}\right), 3.91$ $\left(2 \mathrm{H}, \mathrm{s}, \mathrm{ArCH}_{2}\right), 3.50\left(2 \mathrm{H}, \mathrm{q}, J=7.2 \mathrm{~Hz}, \mathrm{NCH}_{2}\right), 3.40\left(2 \mathrm{H}, \mathrm{q}, J=7.2 \mathrm{~Hz}, \mathrm{NCH}_{2}\right), 2.73(3 \mathrm{H}, \mathrm{s}$, $\left.\mathrm{ArCH}_{3}\right), 2.53\left(3 \mathrm{H}, \mathrm{s}, \mathrm{ArCH}_{3}\right), 1.20\left(3 \mathrm{H}, \mathrm{t}, J=7.2 \mathrm{~Hz}, \mathrm{CH}_{2} \mathrm{CH}_{3}\right), 1.10(3 \mathrm{H}, \mathrm{t}, J=7.2 \mathrm{~Hz}$, $\left.\mathrm{CH}_{2} \underline{\mathrm{C}}_{3}\right) ;{ }^{13} \mathrm{C}$ NMR $\left(100 \mathrm{MHz}, \mathrm{CDCl}_{3}\right) \delta 170.2(\mathrm{C}=\mathrm{O}), 162.6\left(\mathrm{~d},{ }^{1} J_{\mathrm{CF}}=246.3 \mathrm{~Hz}, \mathrm{C}_{\text {quat. }}\right)$, $158.9\left(\mathrm{C}_{\text {quat. }}\right), 157.6\left(\mathrm{C}_{\text {quat. }}\right), 155.1\left(\mathrm{C}_{\text {quat. }}\right), 147.7\left(\mathrm{C}_{\text {quat. }}\right), 144.9\left(\mathrm{C}_{\text {quat. }}\right), 132.9\left(\mathrm{~d},{ }^{4} J_{\mathrm{CF}}=3.2\right.$ $\mathrm{Hz}, \mathrm{CH}), 130.2(2 \mathrm{C}, \mathrm{CH}), 129.4\left(2 \mathrm{C}, \mathrm{d},{ }^{3} J_{\mathrm{CF}}=8.3 \mathrm{~Hz}, \mathrm{CH}\right), 126.9\left(\mathrm{C}_{\text {quat }}\right), 115.6\left(2 \mathrm{C}, \mathrm{d},{ }^{2} J_{\mathrm{CF}}\right.$ $=21.5 \mathrm{~Hz}, \mathrm{CH}), 115.0(2 \mathrm{C}, \mathrm{CH}), 108.3(\mathrm{CH}), 101.0\left(\mathrm{C}_{\text {quat. }}\right), 69.5\left(\mathrm{OCH}_{2}\right), 42.4\left(\mathrm{NCH}_{2}\right), 40.7$ $\left(\mathrm{NCH}_{2}\right), 28.3\left(\mathrm{CH}_{2}\right), 24.7\left(\mathrm{CH}_{3}\right), 17.1\left(\mathrm{CH}_{3}\right), 14.5\left(\mathrm{CH}_{3}\right), 13.2\left(\mathrm{CH}_{3}\right) ;$ LRMS (+ESI) $\mathrm{m} / \mathrm{z}$ $461.07\left([\mathrm{M}+\mathrm{H}]^{+}, 100 \%\right)$; Anal. $\left(\mathrm{C}_{27} \mathrm{H}_{29} \mathrm{~N}_{4} \mathrm{O}_{2} \mathrm{~F}\right)$ : calcd, C 70.41, H 6.35, N 12.17; found, $\mathrm{C}$ 70.47, H 6.40, N 12.01 .

\subsubsection{2-(2-(4-((2-(Trifluoromethyl)benzyl)oxy)phenyl)-5,7-dimethylpyrazolo[1,5- a]pyrimidin-3-yl)- $N, N$-diethylacetamide (25)}

Treating 13 with 2-(trifluoromethyl)benzyl bromide (179 $\mathrm{mg}, 0.75 \mathrm{mmol}, 1.5$ equiv.) according to the general procedure gave $\mathbf{2 5}$ as a colorless crystalline solid (222 $\mathrm{mg}, 87 \%$ ). m.p. $103-105{ }^{\circ} \mathrm{C} ; \mathrm{R}_{f} 0.48\left(\mathrm{CHCl}_{3}-\mathrm{MeOH}, 90: 10\right) ;{ }^{1} \mathrm{H} \mathrm{NMR}\left(400 \mathrm{MHz}, \mathrm{CDCl}_{3}\right) \delta 7.80-7.69$ $(4 \mathrm{H}, \mathrm{m}, \mathrm{ArH}), 7.56(1 \mathrm{H}, \mathrm{t}, J=7.6 \mathrm{~Hz}, \mathrm{ArH}), 7.41(1 \mathrm{H}, \mathrm{t}, J=7.6 \mathrm{~Hz}, \mathrm{ArH}), 7.04(2 \mathrm{H}, \mathrm{d}, J=$ $8.8 \mathrm{~Hz}, \mathrm{ArH}), 6.50(1 \mathrm{H}, \mathrm{s}, \mathrm{ArH}), 5.30\left(2 \mathrm{H}, \mathrm{s}, \mathrm{OCH}_{2}\right), 3.91\left(2 \mathrm{H}, \mathrm{s}, \mathrm{ArCH}_{2}\right), 3.50(2 \mathrm{H}, \mathrm{q}, J=$ $\left.7.2 \mathrm{~Hz}, \mathrm{NCH}_{2}\right), 3.40\left(2 \mathrm{H}, \mathrm{q}, J=7.2 \mathrm{~Hz}, \mathrm{NCH}_{2}\right), 2.73\left(3 \mathrm{H}, \mathrm{s}, \mathrm{ArCH}_{3}\right), 2.53\left(3 \mathrm{H}, \mathrm{s}, \mathrm{ArCH}_{3}\right)$, $1.19\left(3 \mathrm{H}, \mathrm{t}, J=7.2 \mathrm{~Hz}, \mathrm{CH}_{2} \underline{\mathrm{C}}_{3}\right), 1.11\left(3 \mathrm{H}, \mathrm{t}, J=7.2 \mathrm{~Hz}, \mathrm{CH}_{2} \underline{\mathrm{C}}_{3}\right) ;{ }^{13} \mathrm{C} \mathrm{NMR}(100 \mathrm{MHz}$, $\left.\mathrm{CDCl}_{3}\right) \delta 170.2(\mathrm{C}=\mathrm{O}), 158.6\left(\mathrm{C}_{\text {quat. }}\right), 157.6\left(\mathrm{C}_{\text {quat. }}\right), 155.1\left(\mathrm{C}_{\text {quat. }}\right), 147.7\left(\mathrm{C}_{\text {quat. }}\right), 144.9\left(\mathrm{C}_{\text {quat. }}\right)$, $135.9(\mathrm{CH}), 132.3\left(\mathrm{C}_{\text {quat. }}\right), 130.2(2 \mathrm{C}, \mathrm{CH}), 128.7(\mathrm{CH}), 127.6(\mathrm{CH}), 127.4\left(\mathrm{q},{ }^{2} J_{\mathrm{C}-\mathrm{F}}=30.9\right.$ $\left.\mathrm{Hz}, \mathrm{C}_{\text {quat. }}\right), 127.1\left(\mathrm{C}_{\text {quat. }}\right), 125.8\left(\mathrm{q},{ }^{3} J_{\mathrm{C}-\mathrm{F}}=5.7 \mathrm{~Hz}, \mathrm{CH}\right), 124.5\left(\mathrm{q},{ }^{1} J_{\mathrm{C}-\mathrm{F}}=252.6 \mathrm{~Hz}, \mathrm{CF}_{3}\right)$, $115.1(2 \mathrm{C}, \mathrm{CH}), 108.3(\mathrm{CH}), 101.0\left(\mathrm{C}_{\text {quat. }}\right), 66.2\left(\mathrm{q},{ }^{4} \mathrm{~J}_{\mathrm{C}-\mathrm{F}}=3.1 \mathrm{~Hz}, \mathrm{OCH}_{2}\right), 42.5\left(\mathrm{NCH}_{2}\right), 40.7$ $\left(\mathrm{NCH}_{2}\right), 28.2\left(\mathrm{CH}_{2}\right), 24.7\left(\mathrm{CH}_{3}\right), 17.0\left(\mathrm{CH}_{3}\right), 14.5\left(\mathrm{CH}_{3}\right), 13.2\left(\mathrm{CH}_{3}\right)$; LRMS (+ESI) $\mathrm{m} / z$ 
$511.07\left([\mathrm{M}+\mathrm{H}]^{+}, 100 \%\right)$; Anal. $\left(\mathrm{C}_{28} \mathrm{H}_{29} \mathrm{~N}_{4} \mathrm{O}_{2} \mathrm{~F}_{3}\right)$ : calcd, C 65.87, H 5.73, N 10.97; found, $\mathrm{C}$ 65.64, H 5.66, N 10.56.

\subsubsection{2-(2-(4-((3-(Trifluoromethyl)benzyl)oxy)phenyl)-5,7-dimethylpyrazolo[1,5- a]pyrimidin-3-yl)- $N, N$-diethylacetamide (26)}

Treating 13 with 3-(trifluoromethyl)benzyl bromide (115 $\mu \mathrm{L}, 0.75 \mathrm{mmol}, 1.5$ equiv.) according to the general procedure gave $\mathbf{2 6}$ as a colorless crystalline solid (177 g, 69\%). m.p. 120-122 ${ }^{\circ} \mathrm{C} ; \mathrm{R}_{f} 0.45\left(\mathrm{CHCl}_{3}-\mathrm{MeOH}, 90: 10\right) ;{ }^{1} \mathrm{H} \mathrm{NMR}\left(500 \mathrm{MHz}, \mathrm{CDCl}_{3}\right) \delta 7.80(2 \mathrm{H}, \mathrm{d}, J=$ $8.5 \mathrm{~Hz}, \operatorname{ArH}), 7.73(1 \mathrm{H}, \mathrm{s}, \operatorname{ArH}), 7.64(1 \mathrm{H}, \mathrm{d}, J=7.5 \mathrm{~Hz}, \operatorname{ArH}), 7.59(1 \mathrm{H}, \mathrm{d}, J=7.5 \mathrm{~Hz}$, ArH), $7.51(1 \mathrm{H}, \mathrm{t}, J=7.5 \mathrm{~Hz}, \mathrm{ArH}), 7.05(2 \mathrm{H}, \mathrm{d}, J=8.5 \mathrm{~Hz}, \mathrm{ArH}), 6.51(1 \mathrm{H}, \mathrm{s}, \mathrm{ArH}), 5.16$ $\left(2 \mathrm{H}, \mathrm{s}, \mathrm{OCH}_{2}\right), 3.94\left(2 \mathrm{H}, \mathrm{s}, \mathrm{ArCH}_{2}\right), 3.51\left(2 \mathrm{H}, \mathrm{q}, J=7.2 \mathrm{~Hz}, \mathrm{NCH}_{2}\right), 3.40(2 \mathrm{H}, \mathrm{q}, J=7.2 \mathrm{~Hz}$, $\left.\mathrm{NCH}_{2}\right), 2.74\left(3 \mathrm{H}, \mathrm{s}, \mathrm{ArCH}_{3}\right), 2.55\left(3 \mathrm{H}, \mathrm{s}, \mathrm{ArCH}_{3}\right), 1.20\left(3 \mathrm{H}, \mathrm{t}, J=7.2 \mathrm{~Hz}, \mathrm{CH}_{2} \mathrm{CH}_{3}\right), 1.11$ $\left(3 \mathrm{H}, \mathrm{t}, J=7.2 \mathrm{~Hz}, \mathrm{CH}_{2} \mathrm{CH}_{3}\right) ;{ }^{13} \mathrm{C} \mathrm{NMR}\left(125 \mathrm{MHz}, \mathrm{CDCl}_{3}\right) \delta 170.2(\mathrm{C}=\mathrm{O}), 158.7\left(\mathrm{C}_{\text {quat. }}\right)$, $157.6\left(\mathrm{C}_{\text {quat. }}\right), 155.0\left(\mathrm{C}_{\text {quat. }}\right), 147.7\left(\mathrm{C}_{\text {quat. }}\right), 144.9\left(\mathrm{C}_{\text {quat. }}\right), 138.2\left(\mathrm{C}_{\text {quat. }}\right), 130.9$ (q, ${ }^{2} J_{\mathrm{C}-\mathrm{F}}=31.9$ $\left.\mathrm{Hz}, \mathrm{C}_{\text {quat. }}\right), 130.7(\mathrm{CH}), 130.2(2 \mathrm{C}, \mathrm{CH}), 129.2(\mathrm{CH}), 127.2\left(\mathrm{C}_{\text {quat. }}\right), 124.9$ (q, ${ }^{3} J_{\mathrm{C}-\mathrm{F}}=3.8 \mathrm{~Hz}$, $\mathrm{CH}), 124.20\left(\mathrm{q},{ }^{1} J_{\mathrm{C}-\mathrm{F}}=272.2 \mathrm{~Hz}, \mathrm{CF}_{3}\right), 124.16\left(\mathrm{q},{ }^{3} J_{\mathrm{C}-\mathrm{F}}=3.8 \mathrm{~Hz}, \mathrm{CH}\right), 115.0(2 \mathrm{C}, \mathrm{CH})$, $108.3(\mathrm{CH}), 101.0\left(\mathrm{C}_{\text {quat }}\right), 69.3\left(\mathrm{OCH}_{2}\right), 42.5\left(\mathrm{NCH}_{2}\right), 40.7\left(\mathrm{NCH}_{2}\right), 28.3\left(\mathrm{CH}_{2}\right), 24.7\left(\mathrm{CH}_{3}\right)$, $17.0\left(\mathrm{CH}_{3}\right), 14.5\left(\mathrm{CH}_{3}\right), 13.2\left(\mathrm{CH}_{3}\right)$; LRMS (+ESI) $\mathrm{m} / \mathrm{z} 511.07\left([\mathrm{M}+\mathrm{H}]^{+}, 100 \%\right)$; Anal. $\left(\mathrm{C}_{28} \mathrm{H}_{29} \mathrm{~N}_{4} \mathrm{O}_{2} \mathrm{~F}_{3}\right)$ : calcd, C 65.87, $\mathrm{H}$ 5.73, N 10.97; found, C 65.69, H 5.71, N 10.83.

\subsubsection{2-(2-(4-((4-(Trifluoromethyl)benzyl)oxy)phenyl)-5,7-dimethylpyrazolo[1,5- a]pyrimidin-3-yl)- $N, N$-diethylacetamide (27)}

Treating 13 with 4-(trifluoromethyl)benzyl bromide (179 $\mathrm{mg}, 0.75 \mathrm{mmol}, 1.5$ equiv.) according to the general procedure gave 27 as a colorless crystalline solid (199 $\mathrm{mg}, 78 \%$ ). m.p. $145-147{ }^{\circ} \mathrm{C} ; \mathrm{R}_{f} 0.60\left(\mathrm{CHCl}_{3}-\mathrm{MeOH}, 90: 10\right) ;{ }^{1} \mathrm{H}$ NMR $\left(500 \mathrm{MHz}, \mathrm{CDCl}_{3}\right) \delta 7.80(2 \mathrm{H}, \mathrm{d}$, $J=8.5 \mathrm{~Hz}, \mathrm{ArH}), 7.64(2 \mathrm{H}, \mathrm{d}, J=8.0 \mathrm{~Hz}, \mathrm{ArH}), 7.56(2 \mathrm{H}, \mathrm{d}, J=8.0 \mathrm{~Hz}, \mathrm{ArH}), 7.04(2 \mathrm{H}, \mathrm{d}, J$ $=8.5 \mathrm{~Hz}, \mathrm{ArH}), 6.50(1 \mathrm{H}, \mathrm{s}, \operatorname{ArH}), 5.17\left(2 \mathrm{H}, \mathrm{s}, \mathrm{OCH}_{2}\right), 3.91\left(2 \mathrm{H}, \mathrm{s}, \mathrm{ArCH}_{2}\right), 3.50(2 \mathrm{H}, \mathrm{q}, J=$ $\left.7.0 \mathrm{~Hz}, \mathrm{NCH}_{2}\right), 3.41\left(2 \mathrm{H}, \mathrm{q}, J=7.0 \mathrm{~Hz}, \mathrm{NCH}_{2}\right), 2.73\left(3 \mathrm{H}, \mathrm{s}, \mathrm{ArCH}_{3}\right), 2.54\left(3 \mathrm{H}, \mathrm{s}, \mathrm{ArCH}_{3}\right)$, $1.19\left(3 \mathrm{H}, \mathrm{t}, J=7.2 \mathrm{~Hz}, \mathrm{CH}_{2} \underline{\mathrm{CH}}_{3}\right), 1.10\left(3 \mathrm{H}, \mathrm{t}, J=7.2 \mathrm{~Hz}, \mathrm{CH}_{2} \underline{\mathrm{CH}}_{3}\right) ;{ }^{13} \mathrm{C}$ NMR $(125 \mathrm{MHz}$, $\left.\mathrm{CDCl}_{3}\right) \delta 170.2(\mathrm{C}=\mathrm{O}), 158.7\left(\mathrm{C}_{\text {quat. }}\right), 157.6\left(\mathrm{C}_{\text {quat. }}\right), 155.0\left(\mathrm{C}_{\text {quat. }}\right), 147.7\left(\mathrm{C}_{\text {quat. }}\right), 144.9\left(\mathrm{C}_{\text {quat. }}\right)$, $141.2\left(\mathrm{C}_{\text {quat. }}\right), 130.2(2 \mathrm{C}, \mathrm{CH}), 130.2$ (q, $\left.{ }^{2} J_{\mathrm{C}-\mathrm{F}}=32.4 \mathrm{~Hz}, \mathrm{C}_{\text {quat. }}\right) 127.5(2 \mathrm{C}, \mathrm{CH}), 127.2\left(\mathrm{C}_{\text {quat. }}\right)$, $125.7\left(\mathrm{q},{ }^{3} J_{\mathrm{C}-\mathrm{F}}=3.8 \mathrm{~Hz}, \mathrm{CH}\right), 124.2\left(\mathrm{q},{ }^{1} J_{\mathrm{C}-\mathrm{F}}=272.0 \mathrm{~Hz}, \mathrm{CF}_{3}\right), 115.0(2 \mathrm{C}, \mathrm{CH}), 108.3(\mathrm{CH})$, $101.0\left(\mathrm{C}_{\text {quat. }}\right), 69.2\left(\mathrm{OCH}_{2}\right), 42.5\left(\mathrm{NCH}_{2}\right), 40.7\left(\mathrm{NCH}_{2}\right), 28.3\left(\mathrm{CH}_{2}\right), 24.7\left(\mathrm{CH}_{3}\right), 17.0\left(\mathrm{CH}_{3}\right)$, $14.5\left(\mathrm{CH}_{3}\right)$, $13.2\left(\mathrm{CH}_{3}\right)$; LRMS (+ESI) $\mathrm{m} / z 511.07\left([\mathrm{M}+\mathrm{H}]^{+}, 100 \%\right)$; Anal. $\left(\mathrm{C}_{28} \mathrm{H}_{29} \mathrm{~N}_{4} \mathrm{O}_{2} \mathrm{~F}_{3}\right)$ : calcd, C 65.87, H 5.73, N 10.97; found, C 65.91, H 5.76, N 10.97.

\subsubsection{2-(2-(4-Phenethoxyphenyl)-5,7-dimethylpyrazolo[1,5-a]pyrimidin-3-yl)- $N, N$ - diethylacetamide (28)}

Treating 13 with 1-bromo-2-phenylethane (100 $\mu \mathrm{L}, 0.75 \mathrm{mmol}, 1.5$ equiv.) according to the general procedure gave $\mathbf{2 8}$ as a colorless crystalline solid (193 mg, 85\%). m.p. 133-135 ${ }^{\circ} \mathrm{C}$; $\mathrm{R}_{f} 0.42\left(\mathrm{CHCl}_{3}-\mathrm{MeOH}, 90: 10\right) ;{ }^{1} \mathrm{H} \mathrm{NMR}\left(500 \mathrm{MHz} \mathrm{CDCl}_{3}\right) \delta 7.76(2 \mathrm{H}, \mathrm{d}, J=8.5 \mathrm{~Hz}, \mathrm{ArH})$, 7.34-7.29 (4H, m, ArH), 7.26-7.23 (1H, m, ArH), $6.98(2 \mathrm{H}, \mathrm{d}, J=8.5 \mathrm{~Hz}, \mathrm{ArH}), 6.49(1 \mathrm{H}, \mathrm{s}$, $\mathrm{ArH}), 4.22\left(2 \mathrm{H}, \mathrm{t}, J=7.3 \mathrm{~Hz}, \mathrm{OCH}_{2}\right), 3.91\left(2 \mathrm{H}, \mathrm{s}, \mathrm{ArCH}_{2}\right), 3.50\left(2 \mathrm{H}, \mathrm{q}, J=7.2 \mathrm{~Hz}, \mathrm{NCH}_{2}\right)$, 
$3.41\left(2 \mathrm{H}, \mathrm{q}, J=7.2 \mathrm{~Hz}, \mathrm{NCH}_{2}\right), 3.12\left(2 \mathrm{H}, \mathrm{t}, J=7.3 \mathrm{~Hz}, \mathrm{OCH}_{2} \mathrm{CH}_{2}\right), 2.74\left(3 \mathrm{H}, \mathrm{s}, \mathrm{ArCH}_{3}\right)$, $2.54\left(3 \mathrm{H}, \mathrm{s}, \mathrm{ArCH}_{3}\right), 1.20\left(3 \mathrm{H}, \mathrm{t}, J=7.2 \mathrm{~Hz}, \mathrm{CH}_{2} \mathrm{CH}_{3}\right), 1.11\left(3 \mathrm{H}, \mathrm{t}, J=7.2 \mathrm{~Hz}, \mathrm{CH}_{2} \mathrm{CH}_{3}\right) ;{ }^{13} \mathrm{C}$ $\operatorname{NMR}\left(125 \mathrm{MHz}, \mathrm{CDCl}_{3}\right) \delta 170.2(\mathrm{C}=\mathrm{O}), 159.1\left(\mathrm{C}_{\text {quat }}\right), 157.6\left(\mathrm{C}_{\text {quat. }}\right), 155.2\left(\mathrm{C}_{\text {quat. }}\right), 147.7$ $\left(\mathrm{C}_{\text {quat. }}\right), 144.9\left(\mathrm{C}_{\text {quat. }}\right), 138.3\left(\mathrm{C}_{\text {quat }}\right), 130.1(2 \mathrm{C}, \mathrm{CH}), 129.1(2 \mathrm{C}, \mathrm{CH}), 128.6(2 \mathrm{C}, \mathrm{CH}), 127.6$ $(\mathrm{CH}), 126.5(\mathrm{CH}), 125.7\left(\mathrm{C}_{\text {quat. }}\right), 114.8(2 \mathrm{C}, \mathrm{CH}), 108.2(\mathrm{CH}), 100.9\left(\mathrm{C}_{\text {quat. }}\right), 68.8\left(\mathrm{OCH}_{2}\right)$, $42.4\left(\mathrm{NCH}_{2}\right), 40.7\left(\mathrm{NCH}_{2}\right), 35.9\left(\mathrm{CH}_{2}\right), 28.3\left(\mathrm{CH}_{2}\right), 24.7\left(\mathrm{CH}_{3}\right), 17.0\left(\mathrm{CH}_{3}\right), 14.5\left(\mathrm{CH}_{3}\right), 13.2$ $\left(\mathrm{CH}_{3}\right)$; LRMS (+ESI) $\mathrm{m} / z$ 457.13 $\left([\mathrm{M}+\mathrm{H}]^{+}, 100 \%\right)$; Anal. $\left(\mathrm{C}_{28} \mathrm{H}_{32} \mathrm{~N}_{4} \mathrm{O}_{2}\right)$ : calcd, $\mathrm{C} 73.66$, $\mathrm{H}$ 7.06, N 12.27; found, C 73.63, H 7.25, N 12.24.

\subsection{Binding studies}

Mitochondria were prepared as previously described, $[35,36]$ with minor modifications as described below, from kidneys of male Wistar rats killed by cervical dislocation. Kidneys

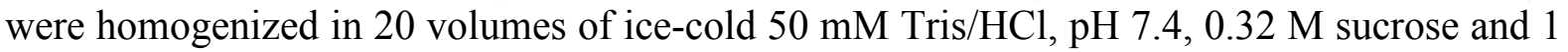
mM EDTA (buffer A), containing protease inhibitors $(160 \mu \mathrm{g} / \mathrm{mL}$ benzamidine, $200 \mu \mathrm{g} / \mathrm{mL}$ bacitracine and $20 \mu \mathrm{g} / \mathrm{mL}$ soybean trypsin inhibitor) with a Teflon pestle in a glass homogenizer and centrifuged at $600 \mathrm{~g}$ for $10 \mathrm{~min}$ at $4{ }^{\circ} \mathrm{C}$. The resulting supernatant was centrifuged at $10,000 \mathrm{~g}$ for $10 \mathrm{~min}$ at $4{ }^{\circ} \mathrm{C}$. The pellet was then resuspended in 20 volumes of ice-cold buffer $\mathrm{A}$ and centrifuged again at $10,000 \mathrm{~g}$ for $10 \mathrm{~min}$ at $4{ }^{\circ} \mathrm{C}$. The crude mitochondrial pellet was frozen at $-20{ }^{\circ} \mathrm{C}$ until the time of assay or incubated with $0.6 \mathrm{nM}$ $\left[{ }^{3} \mathrm{H}\right] \mathrm{PK} 11195$ in $50 \mathrm{mM}$ Tris/HCl, $\mathrm{pH} 7.4$ (buffer B), with a range of concentrations of the tested compounds $(0.1 \mathrm{nM}$ to $10 \mu \mathrm{M})$ in a total volume of $0.5 \mathrm{~mL}$ for $90 \mathrm{~min}$ at $4{ }^{\circ} \mathrm{C}$. The incubation was terminated by dilution to $5 \mathrm{~mL}$ with ice-cold buffer $\mathrm{B}$, followed immediately by rapid filtration through glass-fiber filters (Whatman GF/C). The filters were then washed with buffer B $(2.5 \mathrm{~mL})$ and the amount of radioactivity retained on the filters was determined using a Packard 1600 TR liquid scintillation counter at 66\% efficiency. Non-specific binding was estimated in each case in the presence of $1 \mu \mathrm{M}$ of unlabelled PK11195. The $\mathrm{IC}_{50}$ values were determined and $K_{\mathrm{i}}$ values were derived according to the equation previously derived.[37] Protein concentration was estimated by the method of Lowry and colleagues[38] with bovine serum albumin (BSA) as standard.

\subsection{Cell culture}

Rat C6 glioma cells were cultured in Dulbecco's modified Eagle's medium (DMEM) supplemented with $10 \%$ FBS, $2 \mathrm{mM}$ L-glutamine, 100 units $/ \mathrm{mL}$ penicillin, and $100 \mu \mathrm{g} / \mathrm{mL}$ streptomycin. Cultures were maintained in a humidified atmosphere of $5 \% \mathrm{CO}_{2} / 95 \%$ air at 37 ${ }^{\circ} \mathrm{C}$.

\subsection{Steroidogenesis assay}

C6 cells were seeded in 24-well plates at a density of $\sim 1 \times 10^{6}$ cells/well in a final volume of $1 \mathrm{~mL}$. Prior to measurement of pregnenolone production, the cells were washed three times with a simple salts aqueous medium consisting of $140 \mathrm{mM} \mathrm{NaCl}, 5 \mathrm{mM} \mathrm{KCl}, 1.8 \mathrm{mM} \mathrm{CaCl}_{2}$, $1 \mathrm{mM} \mathrm{MgSO}_{4}, 10 \mathrm{mM}$ glucose, $10 \mathrm{mM}$ HEPES/NaOH, pH 7.4, plus 0.1\% BSA. During experiments, cells were incubated with this simple salts medium in an air incubator at $37{ }^{\circ} \mathrm{C}$. In order to measure pregnenolone secreted into the medium, its further metabolism was blocked by the addition of trilostane $(25 \mu \mathrm{M})$ and SU $10603(10 \mu \mathrm{M})$ (inhibitors of 3 $\beta$ - 
hydroxysteroid dehydrogenase and $17 \alpha$-hydroxylase, respectively) to the simple salts aqueous medium, as previously described.[35] The addition of the compounds to the C6 cells was made by the complete change of the simple salts medium to a medium containing the appropriate concentration $(40 \mu \mathrm{M})$ of compound. The final concentration of ethanol was constant for all the wells within each experiment and did not exceed $0.5 \%(\mathrm{v} / \mathrm{v})$, a concentration which, on its own, had no effect on steroid production. At the end of the incubation period $(2 \mathrm{~h})$, the cell medium was retained and centrifuged at $1500 \mathrm{~g}$ for $10 \mathrm{~min}$. The amount of pregnenolone secreted into the medium was quantified by radioimmunoassay (RIA), using anti-pregnenolone antiserum obtained from ICN Biochemical Inc., CA, USA, under the conditions recommended by the supplier. Cell protein concentration was measured according to a previously described method.[38]

\section{Acknowledgements}

Work performed at The University of Sydney and presented herein was supported in part by the European Union's Seventh Framework Programme [FP7/2007-2013] INMiND (Grant agreement No. HEALTH-F2-2011-278850). 


\section{References}

[1] V. Papadopoulos, M. Baraldi, T.R. Guilarte, T. Knudsen, J. Lacapere, P. Lindemann, M.D. Norenberg, D. Nutt, A. Weizman, M. Zhang, M. Gavish. Trends Pharmacol. Sci., 27 (2006) 402-409.

[2] V. Papadopoulos, J. Liu, M. Culty. Mol. Cell. Endocrinol., 265-266 (2007) 59-64.

[3] M.-K. Chen, T.R. Guilarte. Pharmacol. Ther., 118 (2008) 1-17.

[4] R. Rupprecht, V. Papadopoulos, G. Rammes, T.C. Baghai, J. Fan, N. Akula, G. Groyer, D. Adams, M. Schumacher. Nat. Rev. Drug Discov., 9 (2010) 971-988.

[5] A. Trapani, C. Palazzo, M. de Candia, F.M. Lasorsa, G. Trapani. Bioconjug. Chem., 24 (2013) 1415-1428.

[6] A. Kita, K. Furukawa. Pharmacol. Biochem. Behav., 89 (2008) 171-178.

[7] R. Rupprecht, G. Rammes, D. Eser, T.C. Baghai, C. Schüle, C. Nothdurfter, T. Troxler, C. Gentsch, H.O. Kalkman, F. Chaperon, V. Uzunov, K.H. McAllister, V. BertainaAnglade, C.D. La Rochelle, D. Tuerck, A. Floesser, B. Kiese, M. Schumacher, R. Landgraf, F. Holsboer, K. Kucher. Science, 325 (2009) 490-493.

[8] A.M. Scarf, L.M. Ittner, M. Kassiou. J. Med. Chem., 52 (2009) 581-592.

[9] K. Maaser, M. Hopfner, A. Jansen, G. Weisinger, M. Gavish, A.P. Kozikowski, A. Weizman, P. Carayon, E.O. Riecken, M. Zeitz, H. Scherubl. Br. J. Cancer, 85 (2001) 1771-1780.

[10] A.P. Sutter, K. Maaser, M. Höpfner, B. Barthel, P. Grabowski, S. Faiss, P. Carayon, M. Zeitz, H. Scherübl. Int. J. Cancer, 102 (2002) 318-327.

[11] S. Mukherjee, S.K. Das. Curr. Mol. Med., 12 (2012) 443-457.

[12] X. Wu, K.A. Gallo. PLoS ONE, 8 (2013) e 71258.

[13] M.C. Mendonça-Torres, S.S. Roberts. Cancer Biol. Ther., 14 (2013) 319-326.

[14] C.J.D. Austin, J. Kahlert, M. Kassiou, L.M. Rendina. Int. J. Biochem. Cell Biol., 45 (2013) 1212-1216.

[15] Y. Chen, M. Sajjad, Y. Wang, C. Batt, H.A. Nabi, R.K. Pandey. ACS Med. Chem. Lett., 2 (2010) 136-141.

[16] M. Awad, M. Gavish. Life Sci., 49 (1991) 1155-1161.

[17] E. Briard, S.S. Zoghbi, M. Imaizumi, J.P. Gourley, H.U. Shetty, J. Hong, V. Cropley, M. Fujita, R.B. Innis, V.W. Pike. J. Med. Chem., 51 (2007) 17-30.

[18] D.R. Owen, O.W. Howell, S.-P. Tang, L.A. Wells, I. Bennacef, M. Bergstrom, R.N. Gunn, E.A. Rabiner, M.R. Wilkins, R. Reynolds, P.M. Matthews, C.A. Parker. J. Cereb. Blood Flow Metab., 30 (2010) 1608-1618.

[19] H. Wadsworth, P.A. Jones, W.F. Chau, C. Durrant, V. Morisson-Iveson, J. Passmore, D. O'Shea, D. Wynn, I. Khan, A. Black, M. Avory, W. Trigg. Bioorg. Med. Chem. Lett., 22 (2012) 5795-5800.

[20] D.R. Owen, R.N. Gunn, E.A. Rabiner, I. Bennacef, M. Fujita, W.C. Kreisl, R.B. Innis, V.W. Pike, R. Reynolds, P.M. Matthews, C.A. Parker. J. Nucl. Med., 52 (2011) 24-32.

[21] H. Wadsworth, P.A. Jones, W.F. Chau, C. Durrant, N. Fouladi, J. Passmore, D. O'Shea, D. Wynn, V. Morisson-Iveson, A. Ewan, M. Thaning, D. Mantzilas, I. Gausemel, I. Khan, A. Black, M. Avory, W. Trigg. Bioorg. Med. Chem. Lett., 22 (2012) 1308-1313.

[22] S. Selleri, F. Bruni, C. Costagli, A. Costanzo, G. Guerrini, G. Ciciani, B. Costa, C. Martini. Bioorg. Med. Chem., 9 (2001) 2661-2671.

[23] A. Damont, F. Hinnen, B. Kuhnast, M.-A. Schöllhorn-Peyronneau, M. James, C. Luus, B. Tavitian, M. Kassiou, F. Dollé. J. Labelled Compd. Radiopharm., 51 (2008) 286-292.

[24] A. Reynolds, R. Hanani, D. Hibbs, A. Damont, E.D. Pozzo, S. Selleri, F. Dollé, C. Martini, M. Kassiou. Bioorg. Med. Chem. Lett., 20 (2010) 5799-5802. 
[25] K.R. Leaver, A. Reynolds, S. Bodard, D. Guilloteau, S. Chalon, M. Kassiou. ACS Chem. Neurosci., 3 (2011) 114-119.

[26] C.J. Endres, M.G. Pomper, M. James, O. Uzuner, D.A. Hammoud, C.C. Watkins, A. Reynolds, J. Hilton, R.F. Dannals, M. Kassiou. J. Nucl. Med., 50 (2009) 1276-1282.

[27] C.J. Endres, J.M. Coughlin, K.L. Gage, C.C. Watkins, M. Kassiou, M.G. Pomper. J. Nucl. Med., 53 (2012) 330-335.

[28] N. Arlicot, J. Vercouillie, M.J. Ribeiro, C. Tauber, Y. Venel, J.L. Baulieu, S. Maia, P. Corcia, M.G. Stabin, A. Reynolds, M. Kassiou, D. Guilloteau. Nucl. Med. Biol., 39 (2012) 570-578.

[29] P. Corcia, C. Tauber, J. Vercoullie, N. Arlicot, C. Prunier, J. Praline, G. Nicolas, Y. Venel, C. Hommet, J.L. Baulieu, J.P. Cottier, C. Roussel, M. Kassiou, D. Guilloteau, M.J. Ribeiro. PLoS ONE, 7 (2012) e52941.

[30] M.A. Peyronneau, W. Saba, S. Goutal, A. Damont, F. Dolle, M. Kassiou, M. Bottlaender, H. Valette. Drug. Metab. Dispos., 41 (2013) 122-131.

[31] J.M. Coughlin, Y. Wang, S. Ma, C. Yue, P.K. Kim, A.V. Adams, H.V. Roosa, K.L. Gage, M. Stathis, R. Rais, C. Rojas, J.L. McGlothan, C.C. Watkins, N. Sacktor, T.R. Guilarte, Y. Zhou, A. Sawa, B.S. Slusher, B. Caffo, M. Kassiou, C.J. Endres, M.G. Pomper. J. Neurovirol., 20 (2014) 219-232.

[32] V. Medran-Navarrete, A. Damont, M.A. Peyronneau, B. Kuhnast, N. Bernards, G. Pottier, F. Marguet, F. Puech, R. Boisgard, F. Dolle. Bioorg. Med. Chem. Lett., 24 (2014) 1550-1556.

[33] V. Médran-Navarrete, N. Bernards, B. Kuhnast, A. Damont, G. Pottier, M.-A. Peyronneau, M. Kassiou, F. Marguet, F. Puech, R. Boisgard, F. Dollé. J. Labelled Compd. Radiopharm., 57 (2014) 410-418.

[34] S.D. Banister, S.M. Wilkinson, R. Hanani, A.J. Reynolds, D.E. Hibbs, M. Kassiou. Tetrahedron Lett., 53 (2012) 3780-3783.

[35] G. Campiani, V. Nacci, I. Fiorini, M.P. De Filippis, A. Garofalo, S.M. Ciani, G. Greco, E. Novellino, D.C. Williams, D.M. Zisterer, M.J. Woods, C. Mihai, C. Manzoni, T. Mennini. J. Med. Chem., 39 (1996) 3435-3450.

[36] G. Trapani, M. Franco, L. Ricciardi, A. Latrofa, G. Genchi, E. Sanna, F. Tuveri, E. Cagetti, G. Biggio, G. Liso. J. Med. Chem., 40 (1997) 3109-3118.

[37] C. Yung-Chi, W. Prusoff. Biochem. Pharmacol., 22 (1973) 3099-3108.

[38] O. Lowry, N. Rosebrough, A. Farr, R. Randall. J. Biol. Chem., 193 (1951) 265-275. 
Figure 1. Selected high affinity TSPO ligands.

Scheme 1. Reagents and conditions: (a) ${ }^{i} \mathrm{PrBr}$ (1.5 eq.), $\mathrm{K}_{2} \mathrm{CO}_{3}$ (3.5 eq.), $\mathrm{Me}_{2} \mathrm{CO}$, reflux, 72 h, $100 \%$; (b) $\mathrm{NaH}$ (2 eq.), $\mathrm{MeCN}$ (5 eq.), $\mathrm{PhMe}, 80{ }^{\circ} \mathrm{C}, 18$ h, 67\%; (c) $\mathrm{NaH}$ (2.5 eq.), $\mathrm{BrCH}_{2} \mathrm{C}(\mathrm{O}) \mathrm{NEt}_{2}$, THF, $0{ }^{\circ} \mathrm{C}-\mathrm{rt}, 27 \mathrm{~h}$; (d) $\mathrm{NH}_{2} \mathrm{NH}_{2} \cdot \mathrm{H}_{2} \mathrm{O}$ (2 eq.), $\mathrm{AcOH}$ (1.6 eq.), EtOH, reflux, $13 \mathrm{~h}, 71 \%$ over 2 steps; (e) $\mathrm{CH}_{3} \mathrm{C}(\mathrm{O}) \mathrm{CH}_{2} \mathrm{C}(\mathrm{O}) \mathrm{CH}_{3}$, EtOH, reflux, $20 \mathrm{~h}, 91 \%$; (f) $\mathrm{AlCl}_{3}$ (3.3 eq.), $\mathrm{CH}_{2} \mathrm{Cl}_{2}, 0{ }^{\circ} \mathrm{C}-\mathrm{rt}, 16 \mathrm{~h}, 86 \%$; (g) $\mathrm{RBr}$ (1.5 eq.), $\mathrm{K}_{2} \mathrm{CO}_{3}$ (5 eq.), DMF, $40-50{ }^{\circ} \mathrm{C}, 14-$ 90 h, 37-90\%.

Figure 2. Pregnenolone biosynthesis in rat C6 glioma cells induced by selected TSPO ligands. (Each value represents the mean \pm S.E.M. of $6-9$ replicates; ${ }^{*} P<0.05$, ${ }^{* * *} P<$ $0.001)$.

Figure 3. Correlation between binding affinity and steroidogenic activity for 12, 14-19, and 21-28. 


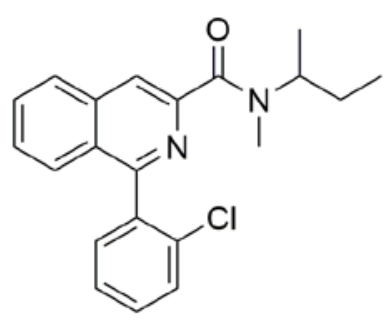

PK11195 (1)

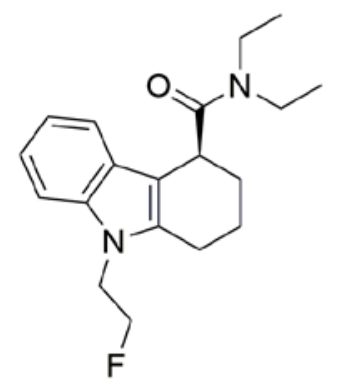

GE-180 (4)<smiles>COc1ccc(OC)c(CN(C(C)=O)c2cc(F)ccc2Oc2ccccc2)c1</smiles>

DAA1106 (2)

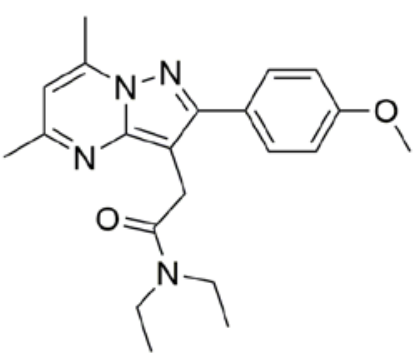

DPA-713 (5)<smiles>COc1ccccc1CN(C(C)=O)c1cnccc1Oc1ccccc1</smiles>

PBR28 (3)

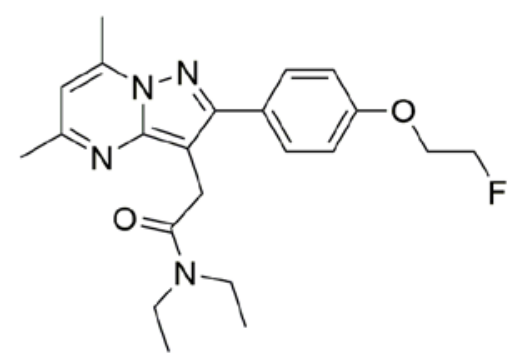

DPA-714 (6) 
$\stackrel{\mathrm{MeO}}{\longrightarrow}$

a $\longrightarrow: R=H$
8: $R={ }^{i} \mathrm{Pr}$

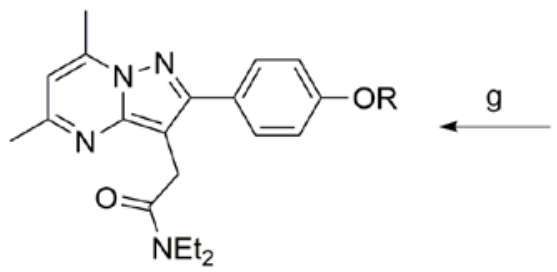

14-28<smiles>CCCOc1ccc(C(=O)CC#N)cc1</smiles>

9

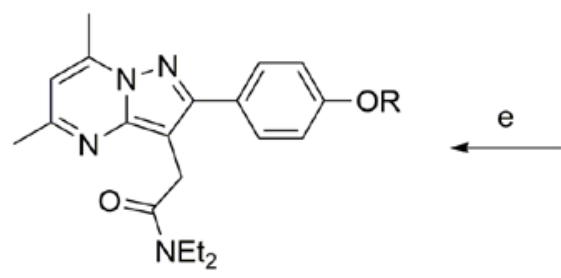

12: $\mathrm{R}={ }^{i} \mathrm{Pr}$

$f \longrightarrow 13: \mathrm{R}=\mathrm{H}$<smiles>CCCOc1ccc(C(=O)C(C#N)CC(=O)NCC)cc1</smiles>

10

$\downarrow d$<smiles>CCCNC(=O)Cc1c(N)n[nH]c1-c1ccc(OCCC)cc1</smiles>

11 


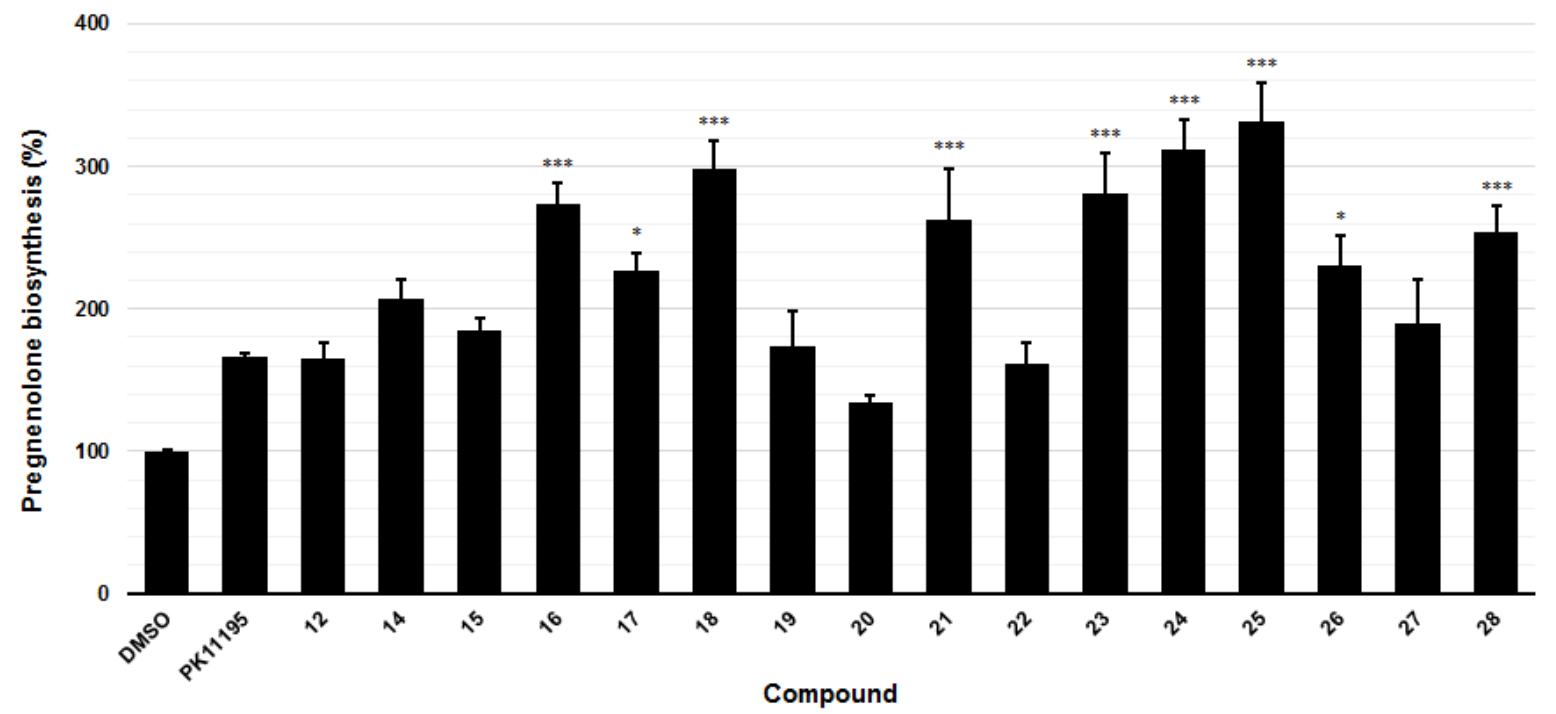




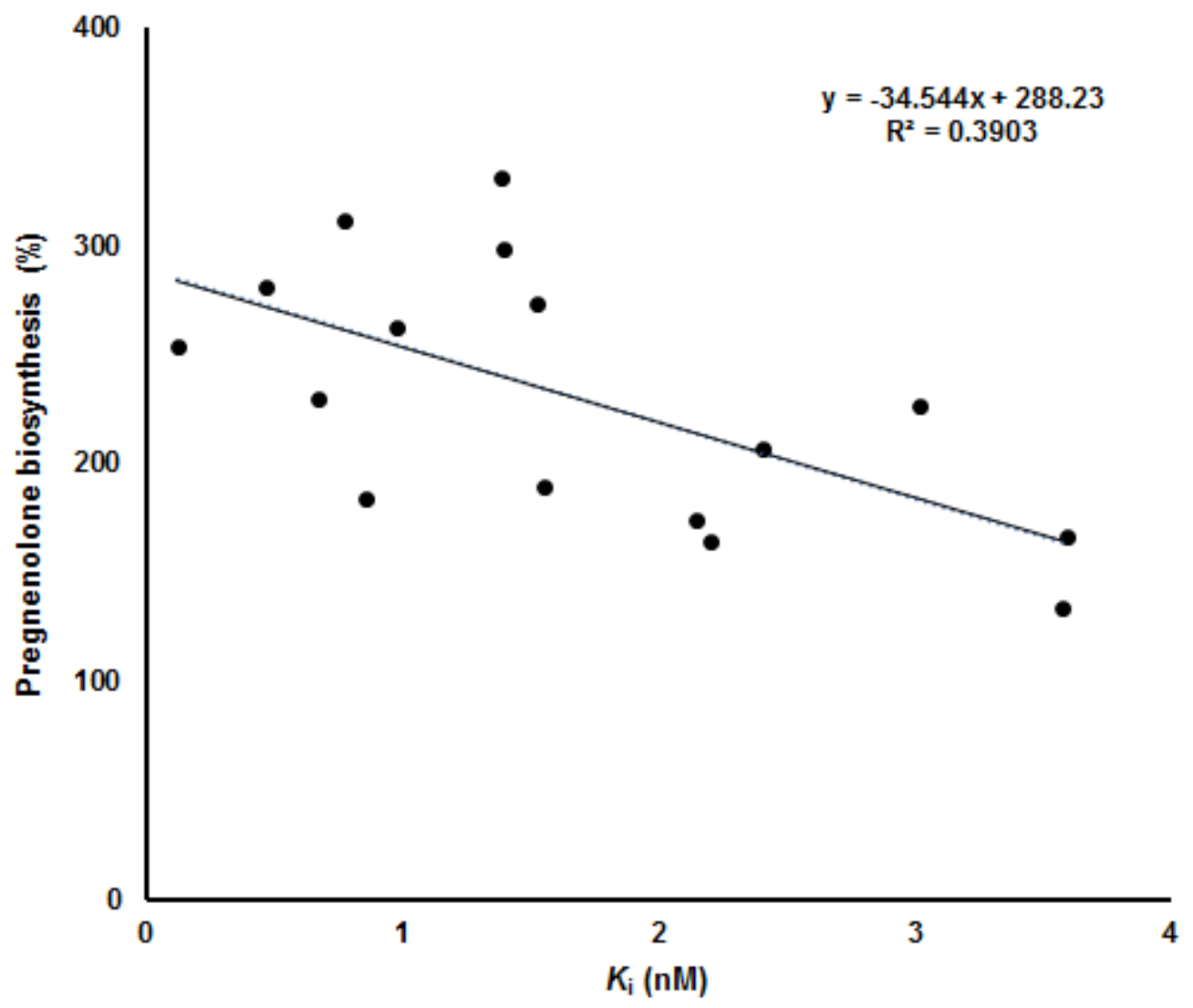




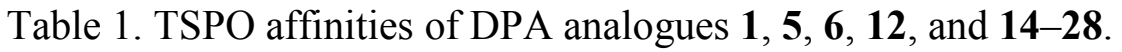

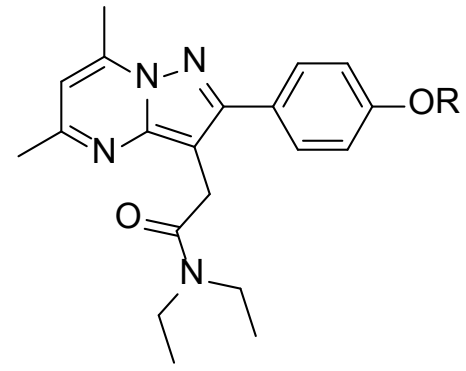

\begin{tabular}{|c|c|c|}
\hline Compound & $\mathrm{R}$ & $\mathrm{TSPO} K_{\mathrm{i}}(\mathrm{nM} \pm \mathrm{SEM})^{\mathrm{a}}$ \\
\hline $\mathbf{1}(\mathrm{PK} 11195)$ & 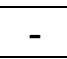 & $9.3 \pm 0.5^{b}$ \\
\hline 5 (DPA-713) & & $4.7 \pm 0.2^{b}$ \\
\hline 6 (DPA-714) & & $7.0 \pm 0.4^{\mathrm{b}}$ \\
\hline 12 & & $2.2 \pm 0.2$ \\
\hline 14 & & $2.4 \pm 0.3$ \\
\hline 15 & & $0.86 \pm 0.08$ \\
\hline 16 & & $1.5 \pm 0.2$ \\
\hline 17 & & $3.0 \pm 0.3$ \\
\hline 18 & & $1.4 \pm 0.2$ \\
\hline 19 & & $2.1 \pm 0.2$ \\
\hline 20 & & $3.6 \pm 0.5$ \\
\hline 21 & & $0.99 \pm 0.09$ \\
\hline 22 & & $0.31 \pm 0.05$ \\
\hline 23 & & $0.47 \pm 0.045$ \\
\hline 24 & & $0.77 \pm 0.08$ \\
\hline 25 & & $1.4 \pm 0.2$ \\
\hline
\end{tabular}




\begin{tabular}{|l|l|l|}
\hline 26 & $0.67 \pm 0.07$ \\
\hline 27 & $0.6 \pm 0.2$ \\
\hline
\end{tabular}

